\title{
Historiografía y novedades del arte mueble Paleolítico en la Península Ibérica
}

\author{
MARIo MENÉndez ${ }^{*}$
}

\begin{abstract}
RESUMEN
ABSTRACT

Este trabajo pretende resumir los numerosos hallazgos realizados en el arte mobiliar paleolítico de la Península lbérica en los últimos años, asi como recoger la abundante bibliografía que se ha generado. Paralelamente a este aumento del registro mobiliar, las últimas excavaciones y nuevas dataciones han cambiado parcialmente la visión de algunas fases paleolíticas,

fudamentalmente el Magdaleniense cantábrico. Esta nueva situación afecta muy directamente a la rígida identificación de temas y convenciones en el arte paleolitico con determinadas fases culturales.

This paper summarizes the latest and numerous findings in Palaeolithic mobiliar art and their historiograhy in the Iberian Peninsula, specially of Cantabrian area. Recent research has considerably changed our knowledge about the diverse phases of Upper Palaeolithic sequence. These new circumstances are changing our perspectives for a better understanding of the mobiliar art.

KEY WORDS

Upper Palaeolithic. Mobile art. Chronology. New trends.
\end{abstract}

\section{PALABRAS CLAVE}

Paleolítico superior. Arte mueble. Cronología. Nuevas tendencias.

* Departamento de Prehistoria e Historia Antigua. UNED. 
De todo el inventario de materiales hallados en la excavación de un yacimiento paleolítico solamente tenemos la certeza de un tipo de objetos que fueron realizados para comunicar algo: el llamado arte mueble. Su posesión y exhibición debió de estar impregnada de contenidos religiosos, mágicos, sociales, estéticos, etc., u otros tan diversos como su propia naturaleza. Esta diversidad implica la dificultad inicial de determinar qué es arte mobiliar, en cuanto realización cargada de contenidos simbólicos, y cuáles son aquellos otros objetos con decoraciones simplemente utilitarias o funcionales. Todas las grandes síntesis de este tipo de arte paleolítico parten de esta distinción - absolutamente subjetiva y generalmente indemostrable- desde la primera clasificación de Cartailhac en 1885, entre objetos utilizados y objetos no utilizados. Será similar la división adoptada por Leroi-Gourhan, en 1965, matizando el carácter de uso precario o prolongado de los primeros, y el componente religioso de los segundos, aunque en ocasiones ambos tipos puedan solaparse. Este último trabajo, al igual que ocurrió con su vertiente rupestre del arte paleolítico, marcará la bibliografía posterior al mismo, hasta el punto de que en ocasiones la historiografía lo toma como referencia para diferenciar toda la bibliografía previa a su publicación, que define como fase pre-estructuralista.

El arte mobiliar, por su propia naturaleza, es susceptible de descontextualización tanto en el espacio como en el tiempo. Las coincidencias significativas entre objetos mobiliares aparecidos en yacimientos muy distantes han sido explicadas como desplazamientos, intercambios, aculturaciones, etc. o como simples fenómenos de convergencia. Igualmente, cuando las similitudes aparecen en ámbitos geográficos restringidos, se han interpretado como referente étnico, en sentido sociolinguístico, de los grupos que las han realizado o del grupo que las porta en los desplazamientos por su red local de yacimientos. No obstante, además de la mencionada subjetividad de análisis, con frecuencia se trata de piezas fragmentadas, a veces reutilizadas en diferentes usos, y sin duda tan diversas en su naturaleza y función que resulta imposible asignarles un significado único, general, como tal arte mueble. A pesar de todo ello, el arte mueble fue tempranamente reconocido como paleolítico y estudiado con gran detalle. Salvo las realizaciones más brillantes, algunas verdaderamente emblemáticas de determinadas fases o yacimientos, pasó a ser una especie de hermano pobre del arte rupestre, a la vez que un fósil director extraordinariamente diagnóstico para algunos períodos del Paleolítico superior. Es decir, un complemento del arte verdaderamente importante - el arte parietal- y de la definición cronológica y cultural de las diferentes ocupaciones paleolíticas de los yacimientos, lo que entonces constituía el objetivo fundamental de la arqueología prehistórica. Sin embargo, en los últi- 
mos años ha cobrado valor en sí mismo, paralelamente a una lectura menos descriptiva y más social del registro arqueológico.

El presente estudio pretende ser una revisión de los últimos hallazgos e interpretaciones del arte mueble paleolítico en la Península Ibérica; si bien la inclusión del arte mueble del ámbito mediterráneo en otro capítulo de este volumen nos excusa de su tratamiento en extensión. Además de esto, la distribución de los hallazgos, el volumen de las publicaciones y la propia formación del autor, confieren un claro sesgo cantábrico a este trabajo. Igualmente, la riqueza de los yacimientos magdalenienses excavados en Asturias en las dos últimas décadas y la actual controversia sobre algunos aspectos de esta fase paleolítica, obligan a dedicarle un espacio más amplio.

\section{EL ÁMBITO CANTÁBRICO}

\section{Reseña historiográfica}

Existen dos corpora fundamentales referidos al arte mueble cantábrico. El primero, realizado por I.Barandiarán (1973a) marcó un hito en la bibliografía sobre el tema, recogiendo de forma crítica todas las piezas conocidas y accesibles en la fecha de su elaboración, ordenándolas en sentido sintético, desde lo particular de los yacimientos a lo general de las conclusiones (técnicas, estilos, evolución, cronología, etc.). El segundo corpus lo debemos a Ma $\mathrm{S}$. Corchón (1986), concebido de forma analítica, desde la generalidad del contexto de cada fase del Paleolítico superior a la particularidad de sus temas, soportes, etc. ordenados por períodos culturales. Ambos configuran la base fundamental de trabajo para el estudio del arte mueble cantábrico, sucesivamente actualizados con obras más específicas por ambos autores, a quienes debemos una parte sutancial de la bibliografía en relación con el tema que nos ocupa.

Como obras generales referidas al arte mueble, con capítulos, menciones o reseñas del arte mobiliar cantábrico, merecen citarse el coloquio celebrado en Foix-Le Mas d'Azil, en Noviembre de 1987, y el catálogo de la exposición L'art préhistorique des Pyrénées (Saint-Germain, en Laye, 1996). En el primero, P.Utrilla reflexiona sobre las bases objetivas para establecer la cronología de determinados temas parietales (1990: 87-99); A. Moure establece relaciones entre arte rupestre y arte mueble (1990a: 207-216), y los excavadores de las cuevas del Nalón y de la Cueva de los Azules presentan sus hallazgos mobiliares en el contexto en que fueron localizados (Fortea y otros, 1990: 219-246). En el segundo, a pesar de 
que su título sugiere un ámbito de análisis restringido al Pirineo, se incluyen yacimientos y obras mobiliares de los principales yacimientos cantábricos, algunas presentes en la exposición del Musée des Antiquités nationales de St Germain-en-Laye (celebrada desde el 2 de abril al 8 de Julio de 1996). En este excelente catálogo aparece un trabajo de P.Utrilla y C.Mazo (1996b: 60-69) sobre diez yacimientos magdalenienses de la vertiente sur del Pirineo y sus obras de arte mueble, en especial Abauntz. A.Moure reflexiona sobre los habitats paleolíticos y el arte (1996b: 72-79); C.González Sainz analiza los últimos momentos magdalenienses y la desaparición del arte paleolítico (1996: 132-139); y L.G. Strauss propone un modelo de ocupación del territorio cantábrico y pirenaico y su repercusión en la aparición de determinadas materias primas o soportes mobiliares (1996: 142-155). La síntesis general del arte mueble cantábrico presente en este catálogo fue realizada por I.Barandiarán (1996a: 88-121), referida no sólo a las novedades de los últimos años sino también al análisis de los soportes, técnicas, temas, estilos, etc., centrado en el mundo magdaleniense. Complementariamente, el catálogo de otra exposición, también francesa, celebrada en Solutrée y dedicada al Solutrense ibérico (Le Solutréen en la Péninsule ibérique) muestra, en trabajo de M.ㄹ. S. Corchón (1994a: 39-74) similar análisis para este período.

Otra obra reciente, de carácter general, que merece citarse es el número especial sobre Arte Paleolítico de la revista Complutum (T. Chapa y M.Menéndez -edit.-1994). Este número, concebido como una síntesis heterogénea y actualizada de algunos temas de arte paleolítico de la $\mathrm{Pe}$ nínsula lbérica, fundamentalmente, al estilo de lo que fue para el resto del arte de Europa Occidental el Proceedings of the Prehistoric Society (A.J. Lawson -edit-) de 1991. En el volumen de Complutum, en lo que se refiere al arte mobiliar cantábrico, I. Barandiarán ofrece una síntesis del estado de la cuestión en la fecha de la publicación (1994: 45-79) con numerosas referencias bibliográficas y soporte gráfico de las novedades; M. ${ }^{2} S$. Corchón presenta los últimos hallazgos en yacimientos asturianos y la nueva interpretación que permite el mejor conocimiento del contexto solutrense y magdaleniense (1994b: 235-264); J. Fernández-Tresguerres resume las características del arte mobiliar aziliense antiguo, directo heredero de tradiciones paleolíticas, y la personalidad del Aziliense clásico (1994: 81-96); M. Cremades reflexiona sobre los procesos tecnológicos, las similitudes y diferencias entre lo figurativo y lo abstracto, y las coincidencias significativas entre diferentes yacimientos (1994: 369-384) y $M$. Menéndez analiza las relaciones entre lo mobiliar y lo parietal en el arte del Paleolítico (1994: 343-335). Con anterioridad A. Moure (1985: 99 129) había realizado una revisión de las novedades aparecidas en el arte 
mueble figurativo, con especial referencia al magdaleniense de Tito BustiIlo. Finalmente, la reciente publicación de la tesis doctoral de G.Adán (1998) sobre la industria ósea del tardiglaciar en Asturias incluye numerosos aspectos colaterales del arte mueble -decoraciones generalmente no figurativas sobre útiles óseos-, bien referenciados en su contexto industrial y faunistico; además de algunas piezas más específicamente referidas al arte mobiliar.

La restante bibliografía tiene un carácter más particular. Bien se refiere a períodos concretos, como el trabajo de I.Barandiarán sobre el Magdaleniense (1988a: 45-60; 1989: 379-396); el de M.ㄹ․ Corchón sobre el Solutrense (1994c: 131-148), o el de A.G. Sieveking (1987) sobre plaquetas grabadas magdalenienses; o bien toma como ámbito de análisis determinadas características, tipos o áreas más restringidas (Barandiarán, 1996b: 345-369; García Guinea, 1986; Corchón, 1991: 35-64; Fernández-Tresguerres, 1990: 47-51; Utrilla, 1995: 281-312) e incluso los propios yacimientos, como veremos más adelante.

Especial relevancia han tenido los recientes trabajos sobre aspectos cronológicos, bien aquellos referidos a dataciones absolutas directas sobre piezas mobiliares (Barandiarán, 1988b: 63-84; Valladas y otros, 1992: 6870); o bien reflexiones sobre los cambios en la interpretación de las fases magdalenienes que la mayor precisión de los métodos de datación absoluta permiten en la actualidad, o la mayor fiabilidad que otorga la combinación de diversos métodos (Corchón, 1995c: 3-19; 1997: 114-143; Moure 1997: 135-142), con clara trascendencia para sus contenidos mobiliares. En relación con esto han sido igualmente significativos diversos trabajos sobre la presencia de determinados temas decorativos, soportes o convenciones en una cronología específica para los mismos (Almagro, 1981; Alonso Silio, 1986; Barandiarán, 1973a y 1973b, 1984; Corchón 1987, 1990b; Fortea, 1983; González Sáinz, 1982; Menéndez y Martínez, 199192; Utrilla, 1990) sobre los que merecerá la pena detenerse más adelante. Igualmente se han publicado trabajos sobre arte mueble $-\mathrm{y} / 0$ rupestrey territorialidad, estacionalidad o geografías sociales, en general (M.W.Conkey, 1980, 1990, 1992; Menéndez y Ocio, 1996; Menéndez y García, 1997; Moure 1994, 1995; Straus, 1982; Utrilla 1994) o con referencias concretas a determinadas áreas cantábricas o grupos de yacimientos. Otros se han centrado en el análisis de determinadas técnicas como el relieve (Corchón, 1987) o la elaboración de colgantes ornamentales (Papi, 1989). Finalmente, se ha propuesto un sistema de análisis de las obras que permite la identificación en algunos casos de diferentes autores, talleres o escuelas en la realización de una o diversas piezas. (Apellániz, 1988, 1989, 1991). 
Inventario de novedades

Ofrecemos a continuación un resumen de los hallazgos más significativos de los últimos años. Debe anticiparse que algunas piezas permanecen en estudio por sus descubridores, aún no han sido depositadas en los museos o han sido sólo parcialmente publicadas, a veces sin aportar dibujos, sino solamente mediante fotografías en noticiarios arqueológicos. Por ello nos limitaremos a constatar su existencia, si bien la mayoría, contrariamente a lo que era frecuente en las piezas extraídas hace algunas décadas, aparecen en contextos bien definidos, lo que ha producido un intenso debate arqueológico profundamente enriquecedor y que ha sacado a los estudios del arte mueble paleolítico cantábrico de la atonía descriptiva en que estaban sumidos.

Comenzamos la relación de Oeste a Este, manteniendo las actuales divisiones administrativas en comunidades autónomas. Tradicionalmente suele señalarse como límite del poblamiento paleoítico cantábrico la zona central de Asturias, lo que se hace extensivo a las manifestaciones artísticas. Desde hace algunos años se han documentado yacimientos paleolíticos y epipaleolíticos en Galicia, si bien es cierto que su importancia todavía no es comparable a los núcleos clásicos cantábricos. Fruto de esta investigación es el descubrimiento de la primera pieza de arte mueble atribuida al paleolítico gallego:

A Pena Grande: Se trata de un yacimiento de superficie situado bajo un antiguo abrigo en Férbedes, en el occidente de la provincia de Lugo, a unos $150 \mathrm{~km}$. de distancia de los yacimientos del área central de Asturias. Junto a un material lítico que podría asignarse por su tipología a un Magdaleniense final (Ramil y Vázquez Varela, 1983), aunque escaso en número y sin elementos óseos definitorios, apareció un colgante realizado en una piedra ovalada (fig. 1: a), con un profundo surco en cada cara y una perforación bicónica, rota, en uno de sus extremos.

En el caso de Asturias deben separarse dos bloques de yacimientos: los correspondientes a la zona central, localizados en la cuenca del río Nalón, y los ubicados en el tercio oriental de la comunidad, bien en la cuenca del Sella o aquellos más próximos a Cantabria.

El valle del Nalón ha ofrecido en las dos últimas décadas un conjunto de hallazgos verdaderamente espectacular, no sólo en lo referido al arte mueble, sino también a la secuencia ocupacional y al arte rupestre, con especial mención a los santuarios exteriores. Merecen destacarse, por sus aportaciones al inventario mobiliar, los yacimientos de Las Caldas, Entrefoces y La Viña. Todos estos yacimientos están situados en las proximi- 
dades de Oviedo, a una distancia media de la linea actual de costa de unos $20 \mathrm{~km}$.

1. Las Caldas: Esta cueva, excavada desde 1971 hasta la actualidad, ha proporcionado una extroardinaria secuencia solutrense y magdaleniense, recogida en una amplia bibliografía general (Corchón, 1981, 1990a, 1992a, 1995a) o referida a aspectos concretos como la cronología (Corchón, 1995c), la industria (Corchón, 1993, 1995b), o el arte mueble (1990b, 1992b, 1994b). Los sedimentos aparecen depositados en tres salas al interior de la cueva (Pasillo, Sala I y Sala II) y al exterior de la misma. No existe una correspondencia entre las diferentes ocupaciones y la denominación de los niveles, lo que dificulta su comprensión global. La secuencia solutrense, en síntesis, puede dividirse en tres unidades, bien datadas y definidas. La inferior corresponde al Solutrense medio, con una datación a base de $19.510 \pm 330$ BP. para el nivel 16, si bien existen otros tres niveles inferiores, que pueden llevar los comienzos del Solutrense medio hasta Würm III final (Hoyos, 1995: 19). Continúa la unidad intermedia, con un Solutrense superior muy clásico y finaliza con un Solutrense superior y terminal en la unidad superior, datado a techo en la base del nivel XIVc en $17.380 \pm 215 \mathrm{BP}$. Es decir, más de dos milenios de ocupación solutrense, que finaliza en el primer tramo del interestadio Lascaux.

Los niveles solutrenses de Las Caldas han proporcionado un conjunto de huesos con decoraciones reticuladas y trazos pareados para el Solutrense medio (fig. 1: b,c,d), a los que se añaden colgantes y alisadores con incisiones en los bordes y series lineales el el Solutrense superior y terminal (fig. 1: e,f). La única figura realista es un caballo esquemático grabado sobre un fragmento de hueso hallado en los niveles solutrenses terminales del exterior de la cueva (fig. $1: \mathrm{g}$ ).

Tras una discordancia erosiva se sitúa el conjunto de niveles del Magdaleniense inferior, facies País Vasco-Occidente, desarrollándose durante el tramo frío inter Lascaux-Anglés. No ha proporcionado una colección mueble destacable, mereciendo citarse un tubo de hueso de ave con incisiones cortas, tema que se repite en otros huesos (fig. 1: h). Sólo entregó como decoración realista un contorno de caballo y dos cabezas de ciervo, todo muy esquemático, grabado sobre un fragmento de asta de muda (fig. 1: i).

El Magdaleniense medio supone en los yacimientos de la zona un verdadero desbordamiento del arte mueble. Las piezas se multiplican, las técnicas y temas se diversifican, etc. En Las Caldas, este período se divide en dos tramos, más frío el primero, y no parece que suponga una continuidad con la fase anterior, pues al enorme incremento en la producción artística se suman diferencias industriales profundas, remarcadas por un 

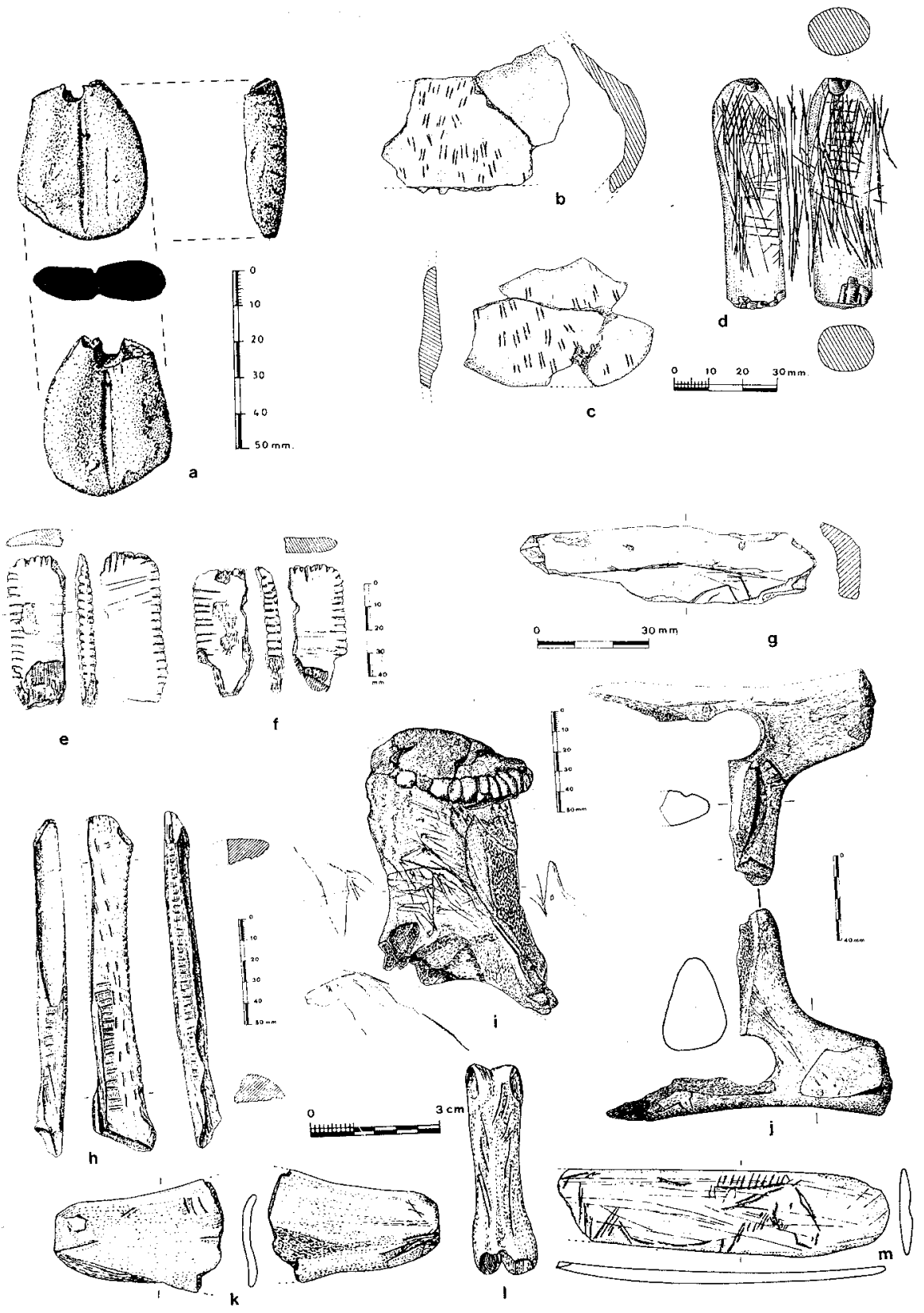

Figura 1. 
hiatus sedimentario entre ambas ocupaciones, lo que le confiere carácter - de verdadera eclosión. El conjunto de dataciones C14 se situa en el tercio central del XIV milenio BP. La colección mobiliar incluye bastones grabados, huesos (fig. 1: j-m) y plaquetas de piedra grabadas con representaciones animales o antropomorfas, destacando algunas por la calidad del trabajo, la rareza de su tema o asociación de motivos (fig. 2: a-j).

Finaliza la secuencia con los niveles del Magdaleniense superior y final, transición que se documenta tempranamente en Caldas -finales de la oscilación Bölling - y que se caracteriza en el arte mueble por un proceso de estilización y abstracción, con variedad de signos y decoraciones lineales.

2. Entrefoces: Este abrigo, situado en el fondo de un desfiladero, muy próximo al cauce del Riosa, ha sufrido numerosos procesos postdeposicionales que han reducido su extensión y alterado parte de la estratigrafía. Excavado desde 1980 hasta 1989 ha proporcionado dos ocupaciones atribuidas al Magdaleniense inferior (González-Morales: 1990; 1992). El nivel inferior, denominado $\mathrm{E}$, se ha definido como Magdaleniense inferior arcaico; mientras el nivel B, datado en $14.690 \pm 200 \mathrm{BP}$. se asigna a un momento avanzado de dicho período; ambos encuadrables en la fase Würm IV-Cantábrico IV, de ambiente "fresco" y progesivamente menos húmedo (Hoyos, 1995: 47). Esta ocupación más reciente del Magdaleniense inferior proporcionó dos piezas muebles de gran interés por la rareza de su tema en el registro paleolítico general: un canto de cuarcita tallado como una cabeza humana, que probablemente haya estado decorada con pintura y otros apliques en su superficie, y un bastón de asta de ciervo (fig. 3: a) esculpido con la figura de un animal indeterminado en su extremo (GonzálezMorales 1990: 32, Fortea y otros 1990: 219).

3. La Viña: Este abrigo, de grandes dimensiones, se abre en una ladera que domina una amplia superficie del valle del Nalón en su cauce medio, en las proximidades de Oviedo. Excavado desde 1980, ha proporcionado hasta la fecha una secuencia casi completa del Paleolítico superior, en sus sectores central y occidental (Fortea 1990; 1992; 1995); así como un complejo santuario exterior de grabados, con restos de pintura, que han sido agrupados en dos horizontes iconográficos relacionables con las ocupaciones auriñacienses y graveto-solutrenses respectivamente (Fortea 1994).

El nivel XIII del sector occidental, definido culturalmente como Auriñaciense $O$ y situado climáticamente a finales del interpleniglacial würmiense (Hengelo-Les Cottés), con una azagaya de base hendida probablemente decorada con muescas más o menos alternas (fig. 3 b), realizadas me- 

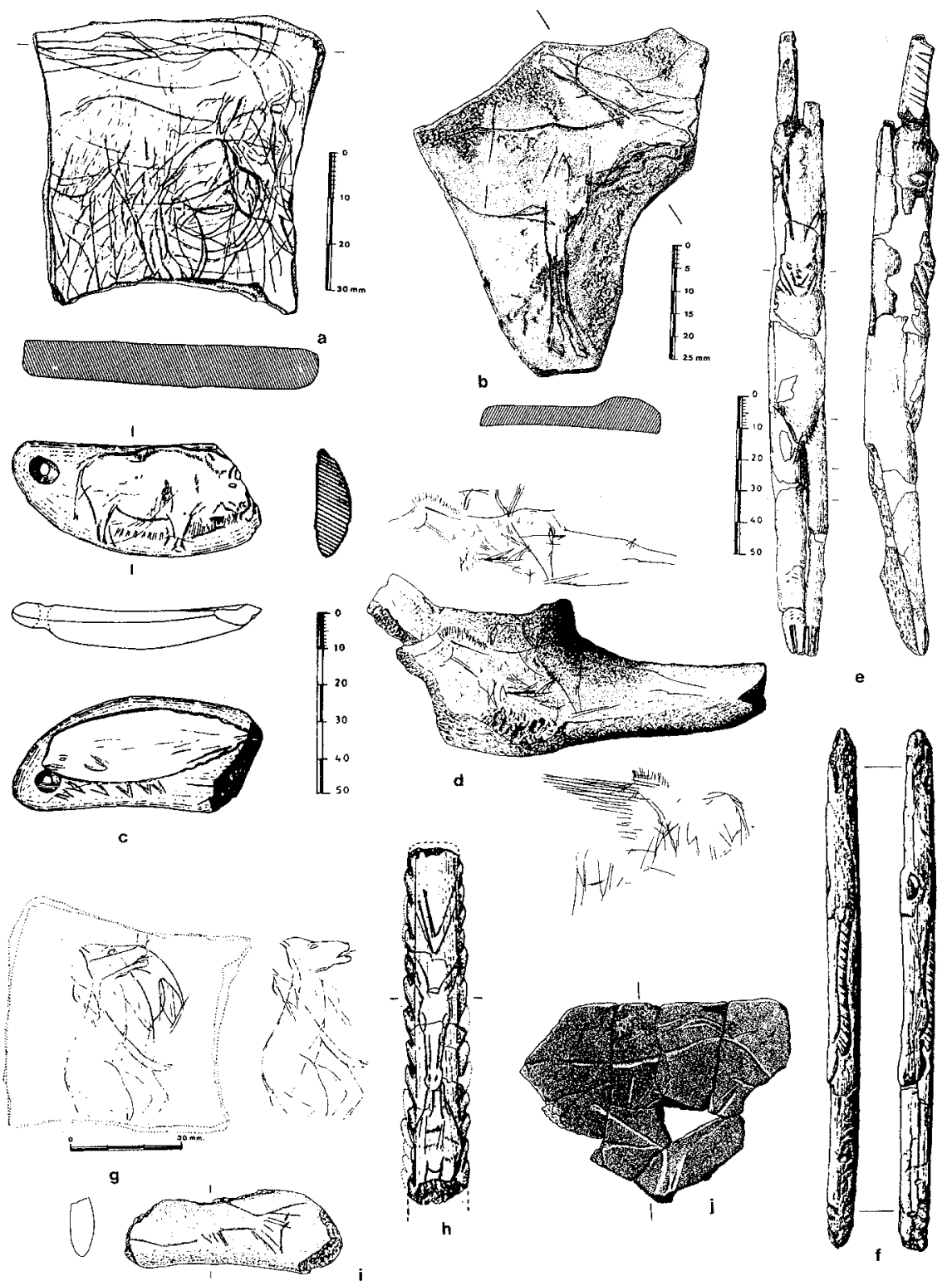

Figura 2. 
diante la técnica que en las descripciones cerámicas se conoce como rocker o pivotante (Fortea, 1995: 23), no habitual en el arte mobiliar paleolítico. Esta ocupación ha sido datada en $36.500 \pm 750$ BP., estando aún precedida por al menos otra de similar identidad cultural. En el nivel XI, igualmente Auriñaciense, se halló un «canto roto con grabado profundo modelante y restos de pintura roja y negra» (1992: 23 , fig. 9). Los niveles auriñacienses han proporcionado también, en el nivel VIII del sector central, tres colgantes, uno de ellos en pizarra (1995: 20).

Los niveles VIII y IX del sector occidental, con ocupaciones perigordienses ricas en buriles de Noailles, entregaron respectivamente un colgante y un fragmento de hueso con un motivo en espiga, una plaqueta con lineas grabadas y un fósil de una planta del Carbonífero, denominada Calamites, que se había recortado y a la que se alteraron artificialmente sus características estrías paralelas (1995: 21).

Las diferentes subdivisiones gravetienses del nivel VI (Vlc y Vlb) enlazan con un Solutrense medio -en términos clásicos- descrito en Vla. Tanto éstos como el Solutrense superior del nivel $V$ no aportaron piezas destacables en el capítulo del arte mobiliar.

El nivel IV de ambos sectores ha sido definido como Magdaleniense medio, asimilable al Magdaleniense IV pirenaico y marca, como en los niveles contemporáneos de la vecina cueva de Caldas, una verdadera eclosión de las artes decorativas mobiliares (Fortea y otros 1990: 222). Se ha situado en el Dryas I superior, con unas dataciones absolutas de $13.360 \pm$ $190 \mathrm{BP}$. y $13.300 \pm 150 \mathrm{BP}$. que resultan ligeramente recientes según la cronología polínica aceptada para la inmediata oscilación Bölling (Hoyos 1995: 51); sin embargo su abundante industria lítica y ósea —con azagayas de base ahorquillada- y su arte mueble, que incluye los elementos más característicos y definitorios, lo configuran como una ocupación paralelizable con el brillante desarrollo del Magdaleniense IV en el suroeste francés(Fortea 1990: 61). En este sentido merecen citarse los tres contornos de caballo recortados en hioides (fig. $3: \mathrm{c}$ ), que han sido temprano elemento de comparación con otros contemporáneos de yacimientos franceses y argumento de territorialidad (Fortea 1983: 349). En la misma linea puede inscribirse un rodete de hueso con entalles en el borde (fig. 3 : d). Como piezas más destacadas de este conjunto merecen citarse un buho tallado en asta (fig. 3: h), un perfil recortado en forma de pez, diversos huesos grabados con figuras animales -incluyendo un reno-, alrededor de un centenar de plaquetas decoradas con motivos geométricos o animalísticos - destacando los caballos con crinera de trazos cortos-, varillas con decoración geométrica o tuberculada, etc. (fig. 3: e-g). 


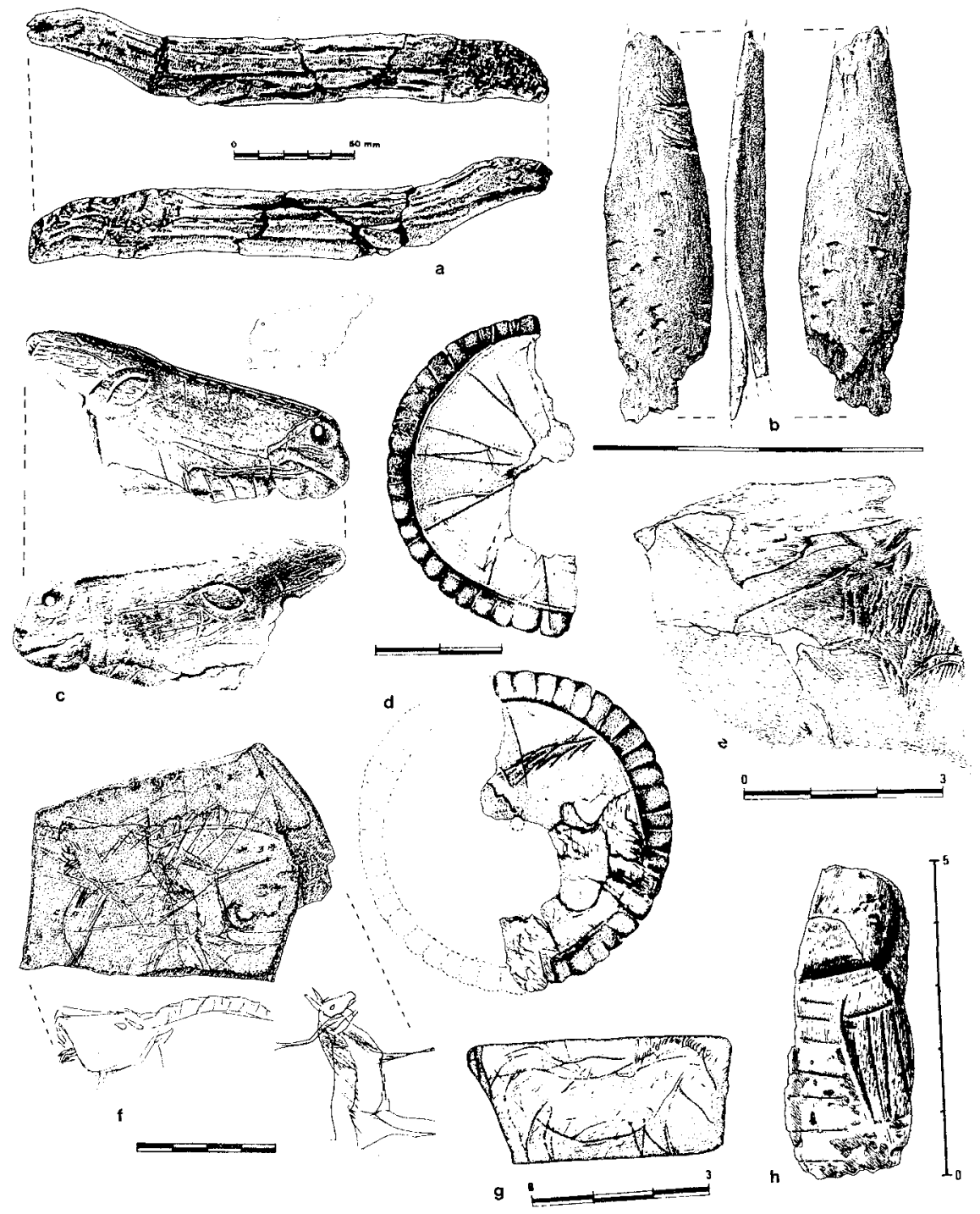

Figura 3. 
4. La Lluera I: Cercana a la cueva de la Viña y muy próxima al cauce del río Nalón se abre esta cueva, que junto con su homónima La Lluera II constituyen dos extroardinarios santuarios exteriores de figuras animales y signos grabados, sin duda relacionados. El primero ofreció una corta estratigrafía ocupacional, con restos solutrenses, magdalenienses finales y azilienses (Rodríguez Asensio 1990: 15-17, Fortea y otros 1990: 239). De la unidad superior de esta última ocupación (Nivel II, A) procede un fragmento de arpón aplanado, con una hilera de dientes, con posible perforación «en ojal» y decoración de bandas oblicuas rellenas de trazos verticales (fig. 4: a). Este nivel ha sido datado en $10.280 \pm 230$ $\mathrm{BP}$., con un tipo de industria similar a Azules 5 y una cronología comparable, por tanto asimilable a un Aziliense antiguo, tal vez aún transicional desde el Magdaleniense final, presente igualmente en ambos yacimientos. Este carácter transicional y la singularidad del arpón descrito, junto con el que veremos en Los Azules, único y ajustado paralelo asturiano, motivan su inclusión en un repertorio que habíamos centrado en el Paleolítico Superior.

5. Cueva Oscura: Próxima al río Andallón, afluente del Nalón en la zona central de Asturias, se localiza esta cueva que fue excavada entre 1975 y 1980. Los resultados fueron parcialmente publicados (Gómez Tabanera y otros, 1975) con especial referencia a algunas piezas de arte mueble (Pérez, 1977; 1982; 1992). La etratigrafía ofreció dos niveles azilienses, con algunos fragmentos óseos que presentaban lineas simples grabadas y algunos cantos pintados en el nivel inferior, denominado 2; así como un nivel clasificado como Magdaleniense superior cantábrico, con arpones de una hilera de dientes, definido como nivel 3. A este último pertenece un fragmento de hueso recortado y raspado, con grabados en ambas caras(Pérez: 1992). En una de ellas muestra una cierva completa entre diversos trazos, mientras en la cara opuesta aparece una cabeza de animal indeterminado y diferentes trazos (fig. 4: d). También a este nivel se atribuye un arpón con la «figura incisa de un bóvido y diversos signos", de la que sólo conocemos su reproducción fotográfica (Gómez Tabanera 1980: 69). Estas representaciones realistas sobre los denominados objetos de uso precario son raras, aunque en este trabajo aportamos algunas conocidas más recientemente (EI Pendo, La Pila) y definidas como serpentiformes, que están a medio camino entre las figuras realistas y los signos, y además se adaptan mejor al campo decorativo visual estrecho y alargado que ofrecen este tipo de soportes. Fuera de contexto se hallaron dos pequeños fragmentos de varilla semicilíndrica (fig. 4: b,c) con decoración geométrica en relieve (Pérez, 1982). 

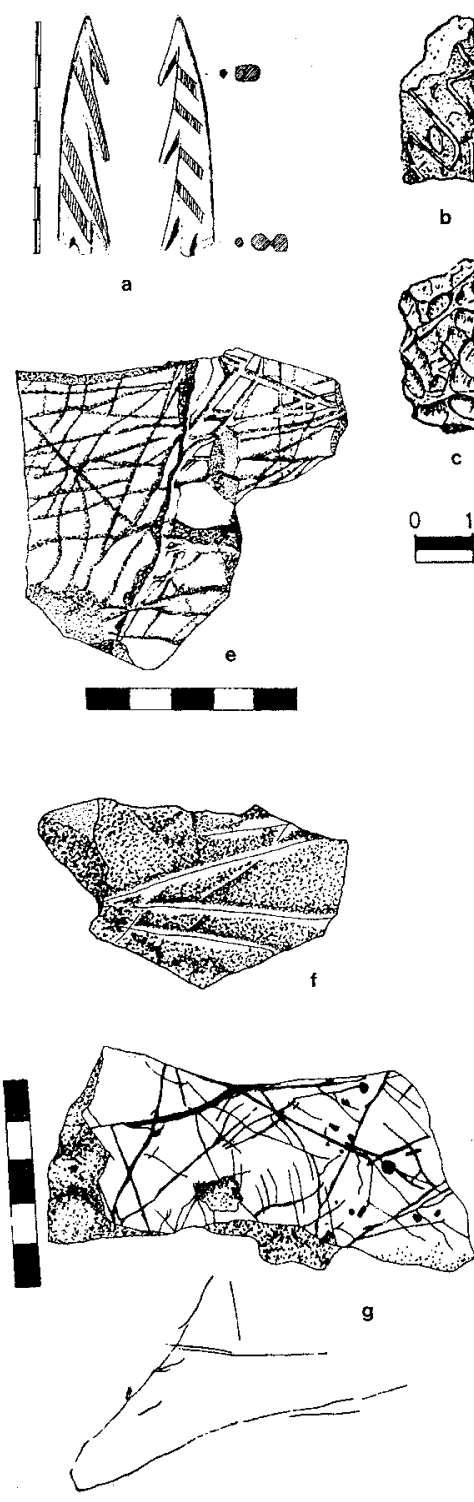

b

c
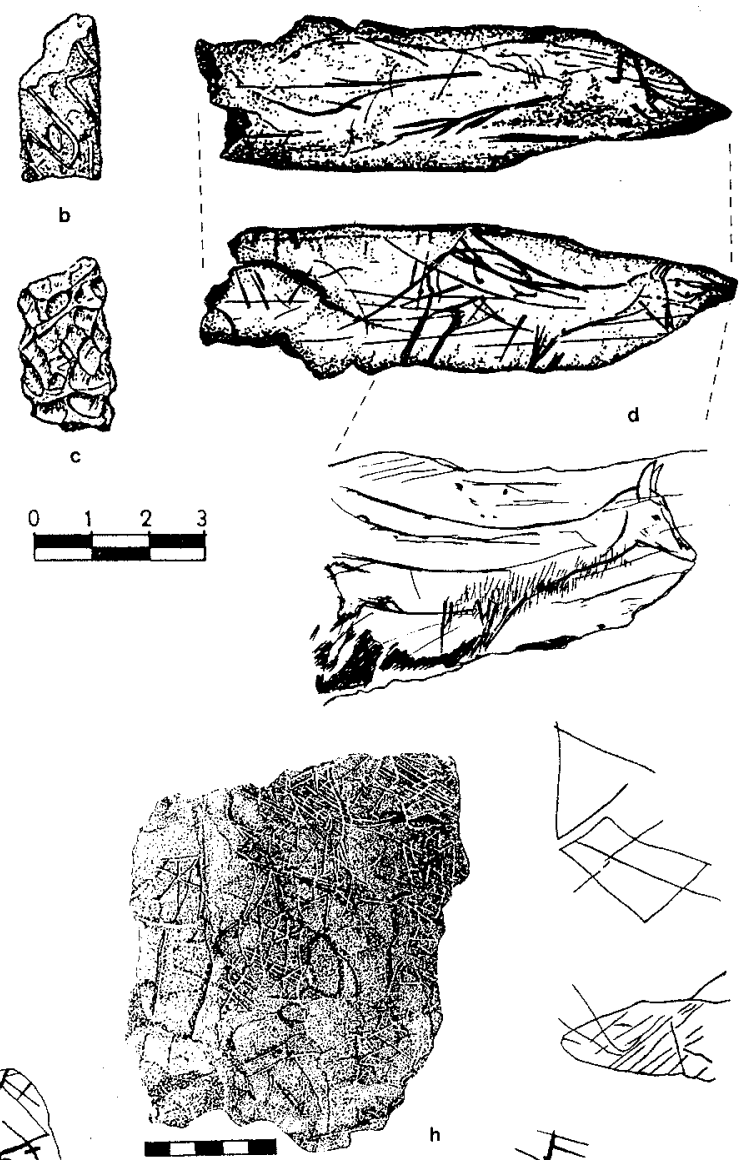<smiles>C=C(C)C(C)(C)C</smiles>

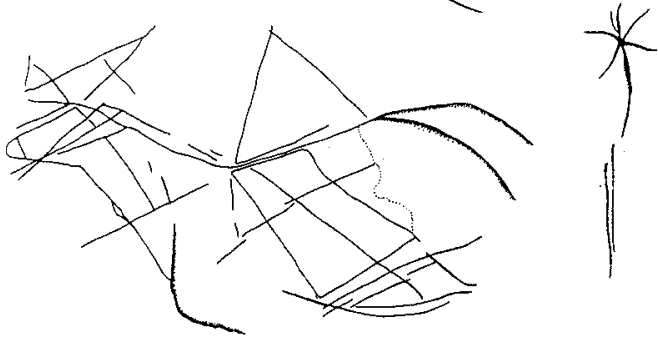

Figura 4. 
La cuenca del río Sella constituye una unidad de análisis territorial para el estudio del Paleolítico Superior de extraordinario valor, con especial significación en los capítulos de arte rupestre y mobiliar, relacionables con los restos de ocupaciones de los grupos que por esta cuenca se movieron durante el Würm reciente. Los yacimientos conocidos hasta la fecha se pueden agrupar en dos grandes conjuntos, muy atomizados respectivamente en el tramo medio del Sella, en torno a la confluencia del río Güeña con éste (Cangas de Onís), y en las proximidades del estuario que configura su desembocadura (Ribadesella).

1. Cueva del Buxu: Situada en el valle del río Güeña, próxima a Cangas de Onís, es conocida por su arte rupestre desde principios de siglo (Obermaier y Vega del Sella, 1918). Excavada desde 1985 a 1989, ha proporcionado restos de ocupaciones estacionales (verano) de cazadores solutrenses superiores durante el Inter Laugerie-Lascaux (Menéndez 1983; $1984 ; 1990 ; 1992)$. Asociadas a ese contexto se han dado a conocer algunas piezas mobiliares (Menéndez, 1992; Menéndez y Olávarri 1983; Menéndez y Ocio, 1997). Dado que los últimos hallazgos son menos conocidos (se han presentado en el II Congreso de Arqueología Peninsular, Zamora 1996) nos permitiremos un análisis más detallado.

La estratigrafía conocida del yacimiento situado en el primer tramo interior de la cueva, ofreció tres niveles de ocupación. Los dos inferiores (niveles 3 y 2) asignables al Solutrense superior y el nivel 1 probablemente al Solutrense terminal. En el abrigo exterior, donde los restos solutrenses y posteriores han desaparecido, se conservan algunos restos de una ocupación antigua, emplazados por debajo de los bloques del derrumbe de la visera de la cueva; derrumbre que se produjo con anterioridad al Solutrense. Por tanto, existió una ocupación asignable, al menos, al Pelolítico superior inicial. Probablemente pueda referirse al Auriñaciense, pues en la vecina cueva de La Güelga existe un nivel datado en $32.000 \pm 1600 / 1350$ BP. cuya industria prospectada no desentona de esa atribución y constituye, por el momento, la más antigua huella de ocupación en la zona.

El capítulo mobiliar del Buxu incluye un conjunto de plaquetas grabadas de gran interés. Dos de ellas (fig. 4: e,f) muestran profundos y anchos trazos, cuyo interior fue colonizado por líquenes; es decir, estuvieron expuestas al exterior, después de ser grabadas, el tiempo suficiente como para sufrir los efectos erosivos de estos microorganismos y la meteorización correspondiente a la exposición subaérea, que sólo presentan en la cara grabada. Por tanto, por su necesaria procedencia de las zonas exteriores y bien iluminadas, parece razonable suponer la existencia de un santuario exterior, relacionable con la ocupación antigua, indeterminada, 
asignada al Paleolítico superior inicial. Estas plaquetas fueron localizadas en la excavación del nivel 3 de la zona interior de la cueva (Solutrense superior). Otras dos plaquetas, de origen exterior y génesis igualmente crioclástica, presentan asociados trazos anchos y profundos con otros más finos, con esquemáticas representaciones animales (fig. $4: \mathrm{g}, \mathrm{h}$ ). Merece destacarse la asociación de un caballo grabado con dos signos - un triángulo y un rectángulo acampanado con división interior, entre una verdadera maraña de otras figuras, líneas grabadas y diaclasas naturales que dificultan su lectura. Más conocida es la escultura de ave -anseriformetallada sobre el colmillo de un Ursus spelaeus (fig. 5: a) probablemente para ser usada como colgante.

2. Cueva de La Güelga: Se localiza al fondo de un valle de montaña, cerrado por un farallón calizo en cuya base se abre la cueva, en la ladera opuesta del valle del río Güeña donde está emplazada la Cueva del Buxu. Excavada desde 1989 a 1993 proporcionó restos de diferentes fases del Paleolítico superior: Auriñaciense, Solutrense y Magdaleniense (Menéndez y Martínez 1992). Merece destacarse el nivel 3c, asignado al Magdaleniense inferior avanzado, facies Juyo, con dataciones que oscilan entre 14. 170 y 14.020 BP., situándose en el límite cronológico entre Magdaleniense inferior/medio, contemporáneo de Juyo 4 , y que como aquel presenta una industria lítica y ósea y un tipo de arte mueble muy en consonancia con esta posición. A este nivel pertenece un interesante conjunto mobiliar, parcialmente conocido (Menéndez y Martínez 1991-92; Martínez y Menéndez 1995) y otra parte aún inédita dada a conocer en el XXIV Congreso Arqueológico Nacional (Menéndez y García: en prensa; Cartagena, 1997).

El mencionado nivel $3 c$ ofreció un fragmento de tibia de ciervo con tres cabezas de cierva grabadas en dos campos decorativos diferentes y en estilos igualmente diversos (fig. 5 : b). La buena datación y contextualización del hueso y la contemporaneidad de las decoraciones ha permitido interesantes sugerencias sobre las convenciones y cronología en el arte mueble paleolítico (Menéndez y Martínez 1991-92) y su extrapolación al arte rupestre en relación con el anterior (Menéndez 1994; González Sáinz 1993). Igualmente dos hioides de cievo perforados y decorados con entalles en el borde (fig. 5: d,e), claramente paralelizables con otros de Tito Bustillo, permiten plantear hipótesis de territorialidad costa-montaña dentro de la cuenca del Sella. Ello es posible, a pesar de la diferente atribución cultural basada en la presencia de un arpón en la unidad inferior de Tito Bustillo (Magdaleniense superior) y la definición de Güelga 3c como Magdaleniense inferior tardío, pues comparten otros muchos rasgos y una posible contemporaneidad (Moure, 1997). Completan la colección de piezas singulares una flauta realizada sobre un hueso de ave (fig. 5: f), con per- 

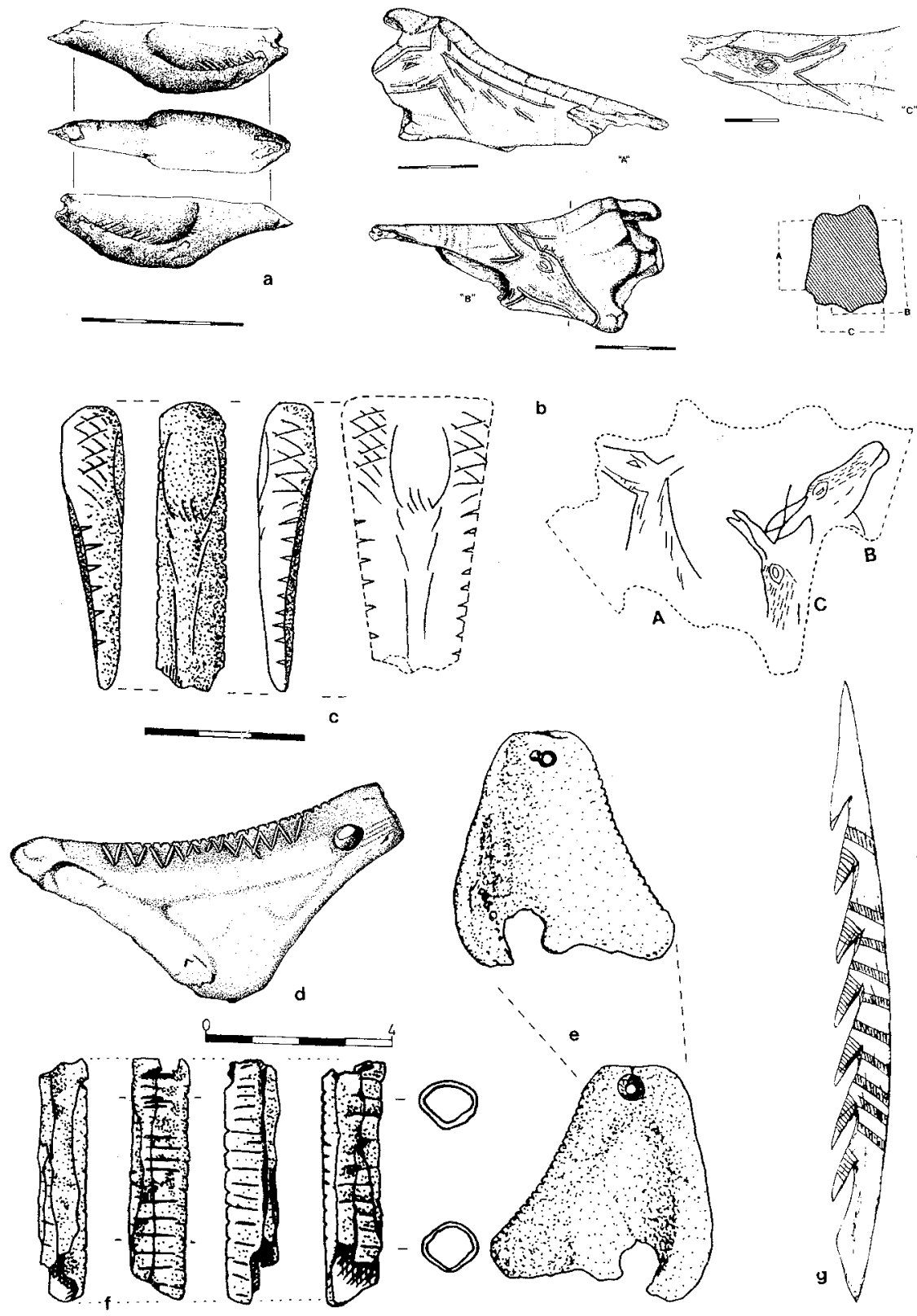

Figura 5. 
foración longitudinal en doble bisel próxima a la boquilla y decoración de lineas cortas, paralelas, perpendiculares al eje de la pieza; así como un probable fragmento proximal de azagaya monobiselada en cuya cara dorsal se grabó una cabra esquemática en visión frotal (fig. 5: c), rodeada por retículas y entalles en los bordes.

3. Cueva de los Azules: En realidad se trata de un conjunto de abrigos, en la actualidad se excava Azules I, situados en la ladera baja del valle en Cangas de Onís, frente a la confluencia del río Güeña con el Sella. Desde 1973 se han excavado hasta 12 niveles diferentes, frecuentemente subdivididos en numerosos tramos o subniveles, que corresponden a ocupaciones azilienses y magdalenienses (Fernández-Tresguerres 1980; 1990; 1992). El nivel 5, definido como Aziliense inicial y emplazado hacia finales del XII milenio, marca la transición desde el arte mueble paleolítico con la existencia de arpones decorados con bandas oblicuas rellenas de trazos cortos, paralelos (fig. 5: g), como la pieza descrita en Lluera I. Abunda en esta idea la existencia de arpones aplanados con perforación circular. Completan el conjunto los característicos cantos pintados, igualmente presentes en el nivel que mejor define al Aziliense pleno, el nivel 3 (cuyas dataciones oscilan entre $9.430 \pm 120 \mathrm{BP}$. para 3a y $10.910 \pm /$ para $3 \mathrm{f}$, en una serie bastante coherente) con otras piezas mobiliares como una espátula con lineas de puntos grabadas en ambas caras. También este nivel proporcionó diversos cantos decorados con puntos o manchas, algunos asociados a un enterramiento humano (Fernández-Tresguerres 1976).

4. Tito Bustillo: Emplazada en la ribera izquierda del estuario que forma el río Sella en su desembocadura, fue descubierta en 1968 y comenzada a excavar en 1972, dentro de un proyecto que incluye el estudio de sus manifestaciones artísticas rupestres y la interrelación de éstas con el yacimiento arqueológico y de ambos con el entorno. La excavación, que se prolongó hasta 1986, se realizó en dos áreas: bajo el gran panel de arte rupestre o área de decoración, y en la antigua entrada de la cueva, hoy cegada por derrumbes, o área de estancia. Estos trabajos han dado lugar a una serie dispersa de publicaciones referidas a determinadas piezas o conjuntos singulares del arte mueble (Moure, 1974; 1979a; 1982a; 1982b; 1982c; 1983; 1984; 1985); así como a publicaciones parciales o avances de la memoria sobre el resultado de las excavaciones, con referencias a lo mobiliar, realizadas por el director de las mismas (Moure 1975; 1976; 1979; 1989; 1990b) o síntesis elaboradas por otros autores (González Sáinz 1989: 35-46).

Las excavaciones más recientes realizadas en el área de decoración no permiten una atribución cultural específica, si bien parece que pueden ponerse en relación con el nivel 1 del área de estancia (Magdaleniense su- 
perior). Proporcionó esta zona un escaso conjunto mobiliar, resumido en una varilla semicilíndrica con algunas lineas grabadas, conchas perforadas y una plaqueta grabada con temas no figurativos, aunque pudiera adivinarse en ella una cabeza animal (fig. 6: a).

El área de estancia ha proporcionado hasta la fecha una estratigrafía que ha sido dividida en dos niveles: el nivel 1, de clima frío y ambiente estepario, identificado con Dyas II; y en nivel 2, de ambiente húmedo y paisaje de bosque, con escasas evidencias antrópicas. El nivel 1, a su vez, ha sido dividido en dos complejos o unidades: el Complejo Superior abarca los subniveles correlativos desde 1a hasta $1 \mathrm{c}^{1}$; el Complejo Inferior incluye los subniveles $1 c^{2}, 1 c^{3}$ y $1 c^{4}$. Ambos complejos presentan una industria lítica homogénea, encuadrable en el Magdaleniense superior, incluyendo los típicos buriles de pico de loro. Sin embargo la industria ósea muestra algunas contradicciones, como la presencia de acanaladuras profundas en las azagayas, bases ahorquilladas y un único arpón - casi protoarpón- en el complejo inferior, frente a los diez de una hilera de dientes del superior (Moure 1982: 112; González Sáinz 1989: 45). A estas contradicciones se suman los resultados de las dataciones absolutas, generalmente envejecidas hasta momentos correspondientes con un Magdaleniense inferior en la región para ambas áreas de excavación y complejos estratigráficos. Esta posición ha sido corroborada por recientes dataciones obtenidas por AMS (Moure, 1997). De modo que han sido definidos como un Magdaleniense medio-superior inicial cantábrico sin solución de continuidad (Moure 1982: 125), con una propuesta de escepticismo sobre la validez del rígido esquema tradicional de fases magdalenienses.

El conjunto de arte mueble extraído de los complejos superior e inferior, constituye una de las grandes colecciones paleolíticas, y en relación con el volumen excavado muestra una riqueza comparable a los yacimientos clásicos franceses. Todas las representaciones zoomorfas figurativas (caballos, ciervas, reno y bisonte) se recogieron en el complejo superior, así como dos posibles esquematizaciones antropomorfas (fig. 6: $d-g$ ).

Existen numerosas decoraciones sobre útiles de tipología: 82 azagayas muestran grabados lineales; varillas semicilíndricas, una de ellas con profundas lineas onduladas en su cara dorsal, mientras otra presenta el posible esquema de un cuerpo femenino (Moure, 1984) (fig. 6: j). Espátulas con caballos grabados, una cola de pez o lineas paralelas y entalles 0 acanaladuras en los bordes (fig. 6: d,h). Un bastón perforado con decoración geométrica (Moure, 1974) (fig. 6: I); arpones decorados y numerosos colgantes realizados sobre huesos hioides (fig. $6: \mathrm{b}, \mathrm{c}$ ), conchas de moluscos marinos o dientes animales con incisiones. 

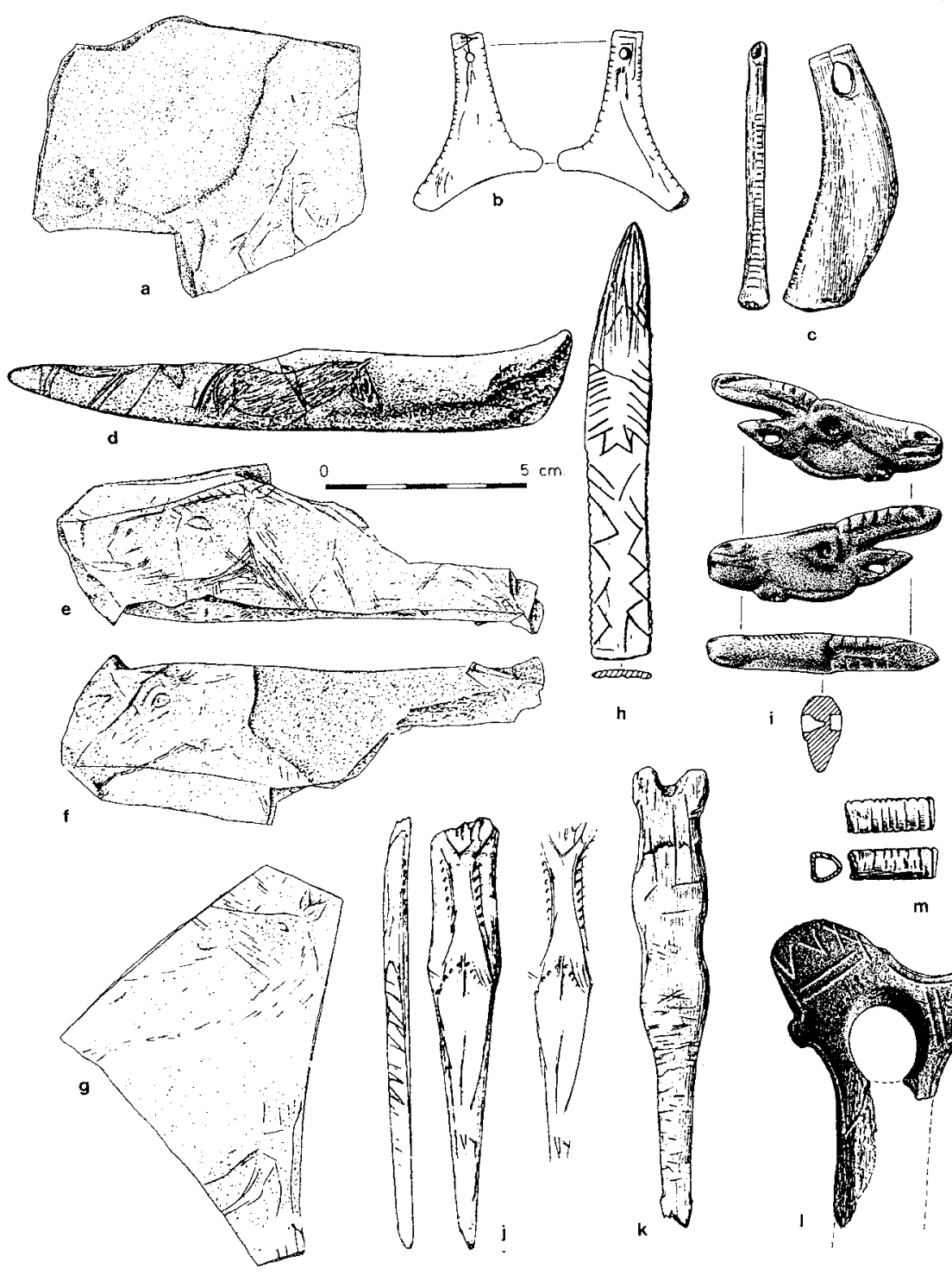

Figura 6. 
Merece destacarse el conjunto de más de ochenta fragmentos de plaquetas decoradas, 12 de las cuales muestran figuraciones animales identificables, localizadas en el sugerente contexto topográfico, inferior a $5 \mathrm{~m}^{2}$, en torno a una fosa en la que se halló una representación femenina esquemática (fig. 6: K), y cuyos grabados animales han podido paralelizarse con una de las fases establecidas en las superposiciones del arte rupestre del gran panel pintado y grabado (Moure, 1985: 103).

Tal vez la pieza emblemática del Magdaleniense superior de Tito Bustillo sea una escultura realizada en asta, que representa una cabeza de cabra con una perforación (Moure, 1983). Su aspecto la asemeja a los contornos recortados típicos del Magdaleniense IV pirenaico, como los vistos en La Viña, pero sin duda su diseño responde a una concepción diferente (fig. 6 : i). Otros colgantes, entre los que destacan los hioides de ciervo decorados con incisiones (fig. $6: \mathrm{b}, \mathrm{c}$ ) pertenecientes al complejo inferior y similares a los descritos en Güelga $3 c$, así como tubos de ave decorados con incisiones paralelas (fig. 6: m), costillas o plaquitas de piedra o marfil grabadas, etc. completan este extraordinario conjunto.

En la zona oriental de Asturias se localiza un importante conjunto de yacimientos arqueológicos y santuarios rupestres que fueron pioneros en la sistematización del Paleolítico superior cantábrico. No obstante, en los últimos años el grueso de los descubrimientos en ambos campos se ha desplazado hacia la zona central de la comunidad, como hemos visto. Notable excepción a este desplazamiento fue el descubrimiento del arte rupestre de la Cueva de Llonín y la posterior excavación de su rico yacimiento arqueológico.

1. Cueva de Llonín: Situada al sur de la Sierra del Cuera, en PeñameIlera Alta, tiene su salida natural hacia la costa a través del valle del río Cares; es decir, hacia la parte más oriental de Asturias, ya en su límite administrativo con Cantabria. Usada con anterioridad para fermentación del queso, se descubrió su arte rupestre en 1971. Comenzaron las excavaciones en 1984, continuando su $\epsilon$ studio en la actualidad, por lo que contamos todavía con escasa información publicada del yacimiento y casi nula documentación gráfica del arte mueble hallado (Fortea, De la Rasilla y Rodríguez, 1990; 1992; 1995). Presenta el especial interés de una amplia secuencia del Paleolítico superior que puede ser paralelizada con las diferentes fases de realización del arte rupestre pintado y grabado en el interior, tarea en la que alguna pieza mobiliar bien contextualizada puede servir de importante apoyo.

El depósito se reparte en cuatro zonas bien diferenciadas: una galería alta y el vestíbulo de la cueva que sin duda tuvieron una potente estrati- 
grafla y generaron un cono de deyección anterior, que ocupó la parte más externa del habitat, y otro cono de deyección interior que desciende hasta la gran sala con arte rupestre. Al fondo de este último se han hallado unas interesantes estructuras con asociaciones de fauna intencionadas, que incluyen craneos de pantera, que sucesivas campañas deberán aclarar si se dispusieron durante el Paleolítico Medio o el Superior inicial, tal vez contemporáneas del nivel $V$ de la Galería, atribuido al Gravetiense(Fortea y otros 1995: 40). Completan la secuencia un Solutrense superior con abundantísima industria lítica típica (nivel IV del vestíbulo y cono posterior y XI del anterior); un posible Magdaleniense inferior en el nivel III de Galería; Magdaleniense medio en el nivel $X$ del cono anterior; continuado por ocupaciones magdalenienses superiores en sus fases iniciales y finales en los niveles IX y VIII respectivamente. La secuencia se completa con algunos restos azilienses.

El arte mueble hallado se describe, con algunas fotografías, en los trabajos citados de 1992 y 1995, pudiendo referenciarse sus piezas más significativas de la siguiente manera: se asignan al Solutrense superior un fragmento proximal de escápula con incisiones paralelas en los bordes y una perforación en el extremo, así como rayas grabadas en el interior del mismo; en esta misma fase se hallaron otros colgantes realizados sobre dientes perforados con incisiones, o cuentas de collar sobre fémures decorados de ave (1995: fig. 4). Algunas varillas y azagayas grabadas, una «losángica de sección planoconvexa muy aplanada con un extraño motivo grabado, cuyo trazo lateral derecho se realizó mediante la técnica pseudoexcisa" (1995: 34, fig. 3). Los niveles pertenecientes al Magdaleniense medio, como podría esperarse, entregaron un conjunto mobiliar rico y característico, destacando un rodete perforado de claros paralelos pirenaicos (fig. 7: a), decorado con círculos concéntricos y radios (1990). Al Magdaleniense superior inicial se asigna un fragmento de costilla con diversos grabados geométricos, una cabra vista de perfil y, al menos, cinco representaciones del típico tema de la cabeza de cabra esquematizada en visión frontal (1992: figs. 7 a y b); junto a esta pieza singular, aparecieron diversos huesos grabados, destacando un metapodio con una cabra grabada (1992: fig. 6).

2. Cueva de La Riera: Conocida y excavada desde los comienzos de la investigación, como su inmediata en Posada de Llanes, Cueto de la Mina. Fue objeto de un proyecto de excavación a finales de los años setenta (1976-79) que proporcionó una interesante estratigrafía solutrense, magdaleniense y aziliense a lo largo de 28 niveles (Straus y otros, 1986). El nivel 24, definido como Magdaleniense final, y datado en $10.980 \pm 430$ BP. proporcionó una pequeña placa ósea con diversos trazos lineales y 

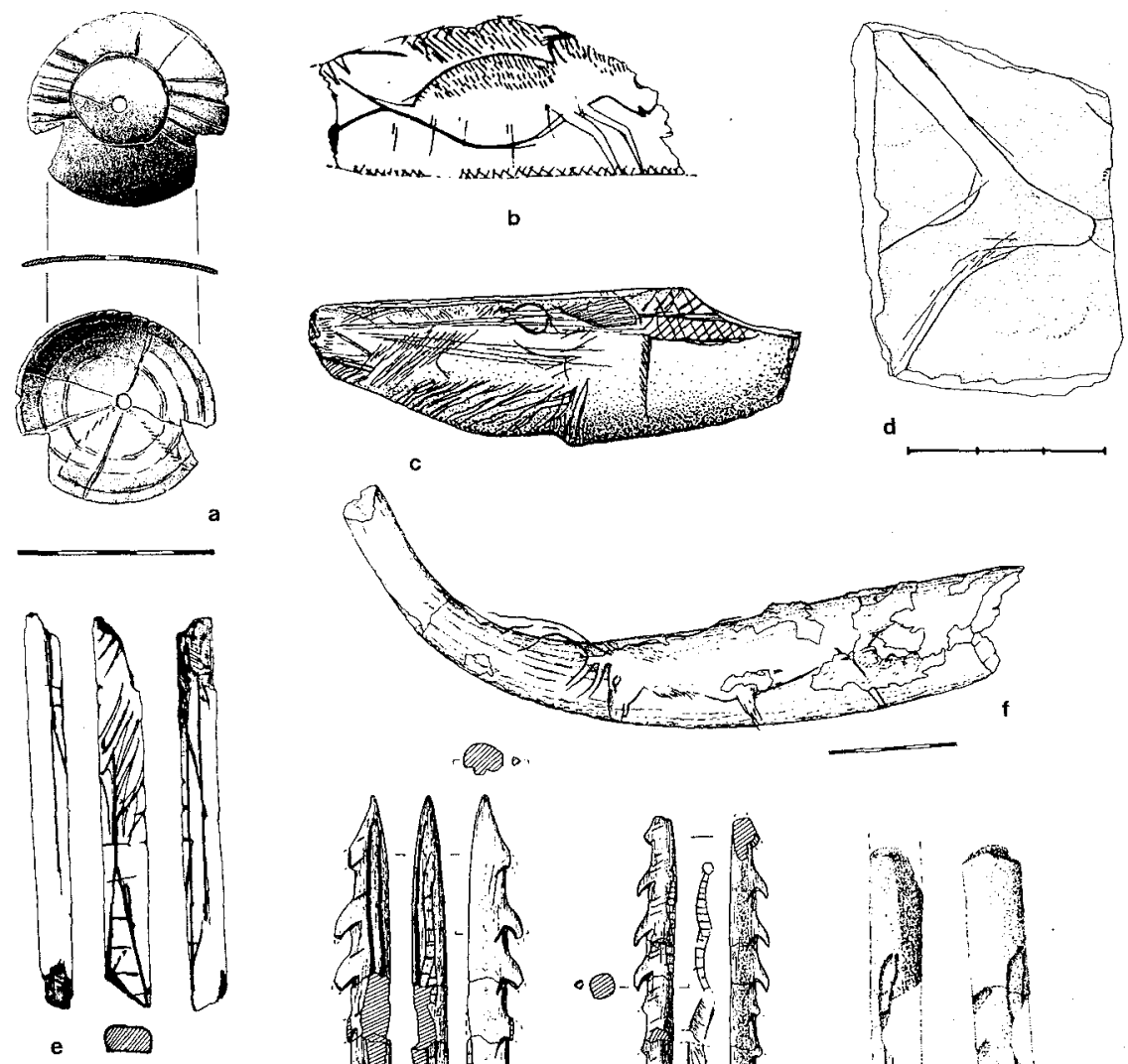
.
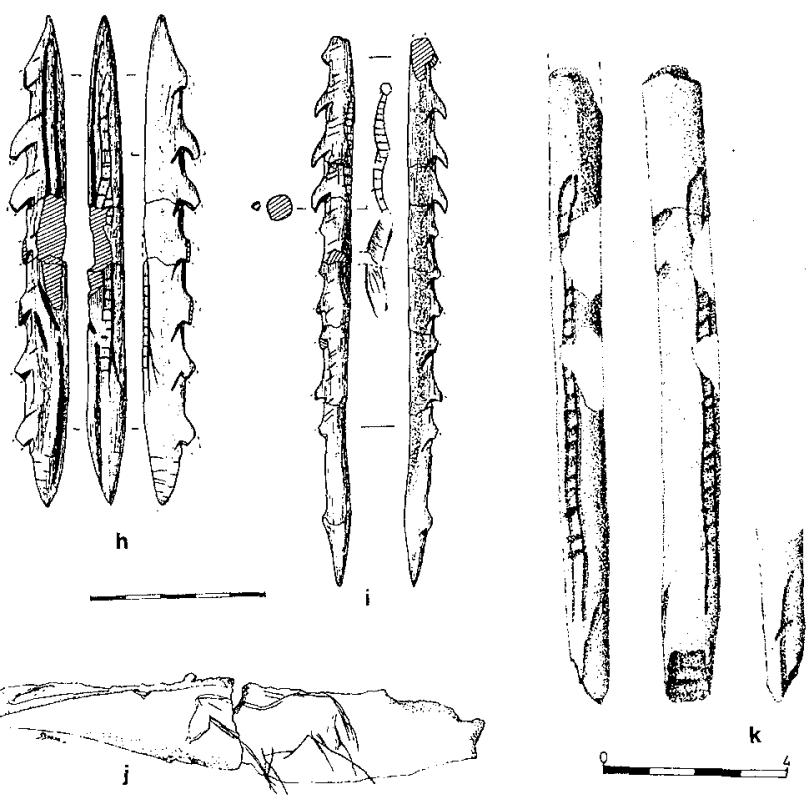

Figura 7. 
aspas, así como un animal grabado (fig. 7: b), de formas fantásticas y difícil clasificación. Pudiera tratarse de la representación de un insecto (González Morales, 1983).

En la comunidad de Cantabria se han producido, igualmente, algunos hallazgos en los últimos años. No obstante no presentan la espectacularidad de los asturianos. Bien es cierto que esta zona central de la cornisa cantábrica ya contaba con un rico patrimonio mobiliar paleolítico desde principios de siglo, con piezas tan emblemáticas como las procedentes de Castillo, Altamira o Pendo.

1. El Juyo: Se abre esta cueva unos $5 \mathrm{Km}$. al occidente de la bahía de Santander. Fue sucesivamente excavada desde 1955, pero el proyecto global de trabajos, que continúa en la actualidad bajo la dirección de J.González Echegaray y L.G.Freeman, comenzó en 1978 (Barandiarán y otros, 1985). Este yacimiento ha proporcionado una extraordinaria secuencia del Magdaleniense inferior cantábrico, a lo largo de más de 14 niveles. Aunque se han hallado numerosos objetos óseos decorados, sobre todo varillas y azagayas, destacan tres fragmentos de hueso con decoración zoomorfa (Freeman y González Echegaray, 1982). Los más antiguos fueron hallados en el nivel 8, con un industria característica del tipo descrito por P.Utrilla como facies Juyo, datada por debajo de $14.440 \pm 180$ BP. (nivel 7). Consisten en dos fragmentos de omóplato grabados respectivamente con una cabeza de caballo y dos animales (una cabeza de cierva y otro indeterminado), que se ven con dificultad entre una maraña de trazos múltiples. La pieza más destacada fue hallada en el nivel 4, muy característico igualmente de la facies Juyo del Magdaleniense inferior, en un momento tardío, $13.920 \pm 240 \mathrm{BP}$., cuando ya en otros yacimientos cantábricos o pirenaicos se está desarrollando el Magdaleniense medio. Se trata de un fragmento de costilla recortado y grabado con la cabeza de una cierva a trazo múltiple (fig. $7: \mathrm{c}$ ). Fue hallado en un contexto descrito como un «santuario", presidido por un bloque grabado con aspecto de máscara (González Echegaray y Freeman, 1981) constituyendo con otros objetos una especie de depósito fundacional (Freeman y González Echegaray, 1982: 164).

2. Cueva de Sovilla: Situada en el valle de Buelna, en la cuenca del Besaya, próxima a Hornos de la Peña y Monte Castillo. Fue limpiada y prospectada en superficie en 1990 y 1991, tratando de salvar parte del yacimiento arqueológico y del arte rupestre que presenta, ambos muy deteriorados (González Sáinz y otros, 1994). Las industrias recogidas en superficie apuntan a una ocupación magdaleniense superior-final. A esta misma época pueden pertenecer las plaquetas de arenisca grabadas, una de ellas con un dibujo muy esquemático de cabra (fig. 7: d). 
3. Cueva de Altamira: La conocida cueva de Santillana del Mar fue excavada durante 1980-81 (Freeman, 1988; González Echegaray, 1988) proporcionando un amplio conjunto óseo, aunque discreto en sus decoraciones, perteneciente al nivel 2. Estas piezas se unen al conjunto del Magdaleniense inferior ya conocidas desde las excavaciones antiguas y de controvertida atribución hasta hace algunos años. El nivel 2, datado en $15.910 \pm 230$ BP., ofreció en esta ocasión una separación nítida del Solutrense superior infrayacente, proporcionando azayas y varillas decoradas con trazos diversos, destacando un fragmento de azagaya con la mitad de un tectiforme de los conocidos como de «tipo Altamira» (Cabrera y Giménez la Rosa, 1991) (fig. 7: e).

4. Cueva de Cualventi: Se abre esta cueva en la localidad de Oreña, a media distancia entre Altamira y la costa. Bajo una gran visera rocosa se excava desde 1976 un yacimiento que hasta la fecha ha ofrecido niveles atribuidos al Solutrense superior, Magdaleniense superior y Magdaleniense final (García Guinea y Rincón, 1978). En 1986 la excavación del Magdaleniense superior (nivel III) proporcionó un bastón perforado de considerable tamaño $(30 \mathrm{~cm}$.), grabado con la figura de un ciervo con larga cormamenta (fig. 7: f). No se acompaña la publicación de esta figura de otros grabados en la misma pieza, pero se describe someramente un contexto asociado a la misma que incluye un rodete de pizarra y un punzón de hueso, todo ello junto a un hogar. El diseño general de la pieza es comparable al conocido bastón perforado de la Cueva del Castillo, pero los detalles y las convenciones en la representación del ciervo lo relacionan igualmente con los bastones de Pendo y Valle, según el descubridor (García Guinea, 1986). También se ha dado a conocer un fragmeto de bastón perforado procedente del Magdaleniense inferior - Beta- de la Cueva del Castillo, con una somera decoración lineal formando retícula (Fernández lbáñez y otros, 1993).

5. Cueva de La Pila: Se encuentra este yacimiento muy próximo a la desembocadura del río Besaya, er la localidad costera de Cuchía, al oeste de Santander. Aunque los trabajos no han finalizado, contamos con alguna publicación preliminar (Lagüera, 1991) que da a conocer su arte mueble con someras referencias al contexto (Gutiérrez y otros, 1986/87; Bernaldo de Quirós y otros 1992). Así, se han identificado hasta el momento dos grandes conjuntos culturales asignables respectivamente al Aziliense (nivel de conchero) y al Magdaleniense superior-final (presencia de arpones de una hilera de dientes). En el conjunto inferior, junto a numerosas piezas óseas con decoraciones lineales no figurativas, entre las que destaca una espátula con diversos trazos, apareció un caballo grabado sobre un fragmento de coxal de ciervo y un arpón con una figura de serpiente y 
un huso relleno de lineas grabadas (nivel IV-3) (fig. 7: j,h). Sobre un fragmento de azagaya se grabó una decoración reticulada y diversas líneas descritas como partes de un pez (nivel IV-1) (fig. 7: g). Otro arpón similar al anterior, con una figura de serpiente grabada (fig. 7: i) fue hallado en el nivel III-4b, igualmente Magdaleniense superior-final.

6. Cueva del Pendo: Situada en Escobedo, a unos $8 \mathrm{~km}$. en linea recta de la costa actual, se abre esta cueva, clásica en los estudios sobre Paleolítico medio y superior. A la publicación definitiva de su discutida estratigrafía (González Echegaray, 1980) se suma recientemente la aparición de arte rupestre, casi desconocido hasta 1997, salvo un par de aves grabadas al fondo de la cueva, ya descubiertas por Alcalde del Rio en 1907. Igualmente se ha localizado un modesto conjunto óseo en el Museo de Valencia, donación del Padre Carballo al S.I.P. en 1950, que permanecía inédito. En el estudio de este material (Aura, 1986) destaca una gruesa azagaya con un largo motivo serpentiforme (fig. $7: \mathrm{k}$ ). Probablemente deba atribuirse al nivel 2, Magdaleniense superior, que proporcionó el extraordinario conjunto mobiliar bien conocido, en el que sobresale el bastón perforado con cabezas de cierva grabadas, una de las piezas emblemáticas del Paleolítico cantábrico.

Similar procedencia tiene un conjunto óseo depositado en el Departamento de Prehistoria y Arqueología de la Universidad de Santiago de Compostela (Villar, 1994), donde se encuentran algunos colgantes, azagayas y arpones con decoraciones lineales, destacando una varilla semicilíndrica con series de trazos en V.

7. Cueva del Rascaño: Esta cueva del valle del Miera, próxima al pueblo de Mirones, era conocida y fue excavada desde principios de siglo. En 1974 se realizó una campaña de excavación y verificación de la estratigrafía dada a conocer con anterioridad, apareciendo en el curso de tales trabajos algunas piezas mobiliares de gran interés (Barandiarán y González Echegaray, 1979; González Echegaray y Barandiarán, 1981). La secuencia ocupacional del yacimiento incluye niveles azilienses (nivel 1) y una sucesión completa del magdaleneiense (niveles 2 a 5).

Entre un amplio conjunto de azagayas, arpones y varillas decoradas con diferentes trazos o motivos simples, así como colgantes de diferentes tipos, correspondientes a las sucesivas fases magdalenienses (1981: 97164), merecen destacarse las siguientes piezas: un omóplato de cabra que presenta los cuartos traseros de un animal, quizá un bisonte, grabado con trazo múltiple y técnica de sombreado o relleno interior (fig. 8: a). Fue hallado fuera de contexto, en la limpieza de las tierras removidas en excavaciones antiguas. No obstante, por su posición en los sedimentos y 
paralelos con otras piezas similares se le asignó a los niveles 4 o 5, Magdaleniense antiguo, datados respectivamente en $12.896 \pm 137 \mathrm{BP}$. y $15.173 \pm 160$ BP. $(1979: 126 ; 1981: 117)$. De la parte superior del nivel 2 (Magdaleniense final, datado en $10.486 \pm 90 \mathrm{BP}$.) procede un fragmento de metapodio de ciervo, primeramente interpretado como una costilla (fig. 8: c), sobre el que se recortó y perforó un colgante con lineas verticales grabadas con puntos adosados (1979: 130; 1981: 115). Finalmente destacamos en el subnivel $4 \mathrm{~b}$ un tubo de hueso de ave, con lineas paralelas perpendiculares al eje del mismo (fig. 8: b), claro paralelo de otra pieza citada en el Magdaleniense inferior de la cueva de la Güelga.

8. Cueva de La Chora: Situada en la cuenca baja del río Asón, presenta restos epipaleolíticos y del Magdaleniense final. Entre estos últimos se recogió un disco de ocre de forma lenticular, interpretado como un útil para colorear crines o hilos (González Echegaray y otros, 1963). Posteriormente se observó que presentaba una cabeza de caballo, grabada en su cara convexa (fig. 8: d), donde aparecen los trazos y desgastes del uso que se ha atribuido a la citada pieza (San Juan, 1983).

En el País Vasco no han aparecido en los últimos años piezas mobiliares excepcionales. En la publicación de la Cueva de Ekain (Altuna y Merino, 1984) estudia A.Baldeón un conjunto óseo que incluye algunas piezas decoradas con lineas someras o incisiones profundas pertenecientes al Aziliense, cuya escasez en decoraciones las hace más destacables (fig. 8: $f, g$ ). Similares decoraciones aparecen en el Magdaleniense superior del nivel $\mathrm{VI}$, con arpones decorados con líneas o trazos en $\mathrm{V}$, destacando una varilla grabada con el tema de la cabra esquemática en visión frontal (fig. 8: e) (Baldeón, 1984: 196). A este mismo nivel pertenece la extraordinaria plaqueta grabada con la superposición de ciervo-caballo,cabra (J.M.Barandiarán y Altuna, 1977: 44), que más recientemente ha dado lugar a precisiones sobre la autoría en el arte mueble paleolítico (Apellaniz, 1989).

En la Cueva de Urtiaga era conocida una plaqueta de arenisca con decoraciones, perteciente al nivel $D$, Magdaleniense final, a la que se han añadido otros fragmentos que la completan (González Sáinz, 1984; 1989: 131), de modo que en la actualidad presenta una cabeza de cabra, un reno y dos cadrúpedos indeterminados (fig. 8: h). Algo más reciente, aunque ya situado en el Aziliense a juzgar por la presencia de arpones característicos, es el nivel VIII del yacimiento guipuzcoano Anton Koba, en Oñati, con una temprana cronología, situada en $11.800 \pm 330 \mathrm{BP}$., en el cual A.Armendáriz (1991: 99; 1992: 190-93) localizó dos azagayas con decoración de incisiones, una costilla grabada con lineas paralelas y un compresor de piedra con diversos grabados de difícil lectura (fig. 8: i). 

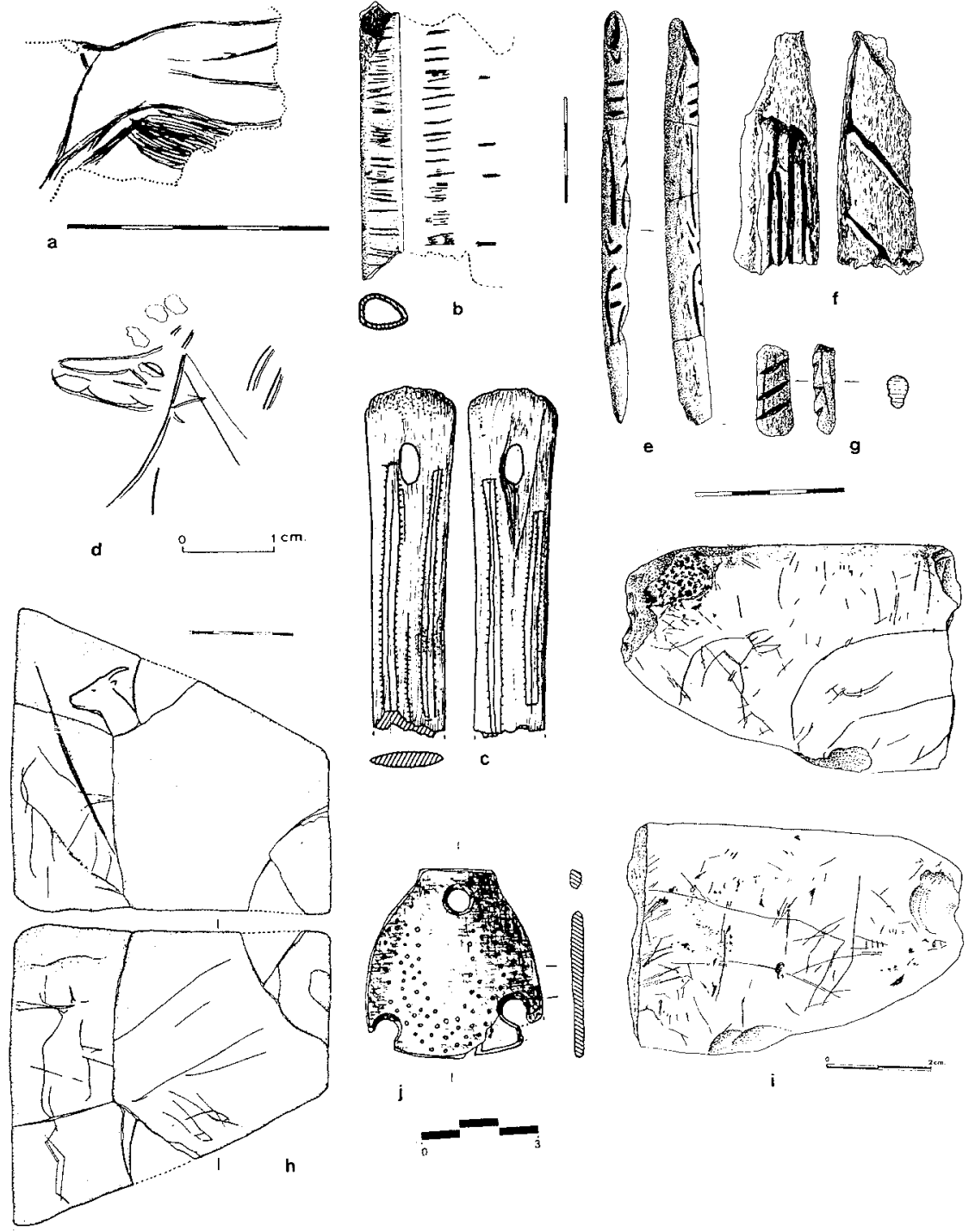

Figura 8 . 
En un covacho de municipio vizcaíno de Berriatua, próximo a Lekeitio, denominado Laminak $/$, se recogió fuera de contexto un colgante de hueso de forma trapezoidal, obtenido de una escápula de caballo (fig. 8: j), sobre el que se grabaron lineas de puntos y se realizaron tres perforaciones (Arribas y Berganza, 1988a, 1988b: 81-83). Se asigna con probabilidad al Magdaleniense final y se ha intentado percibir en las lineas de puntos ritmos numéricos o asociaciones significativas.

La vertiente sur de Los Pirineos ha ofrecido en los últimos años un interesante conjunto de yacimientos magdalenienses y epipaleolíticos, con aportaciones al artre paleolítico tanto más interesantes por su anterior ausencia absoluta; ausencia que dio lugar a la formulación de hipótesis explicativas del poblamiento desde Europa de la Península ibérica y del desplazamiento de los grupos humanos por las plataformas costeras a ambos lados del Pirineo. El conjunto de ocupaciones ahora documentadas, que supera la docena, invalida estas hipótesis e integra tales yacimientos con áreas bien conocidas. Así el conjunto de yacimientos del norte de Navarra presenta claros paralelos con los ya clásicos del Pirineo y de la costa cantábrica, en especial con algunos que ocupan las posiciones más occidentales, de reciente excavación en Asturias (Caldas, Viña y LLonín). Por el contrario, los ubicados en el Pre-Pirineo aragonés presentan más afinidades con el paleolítico mediterráneo catalán (Utrilla, 1995, 1996b). Entre los primeros merece especial mención la Cueva de Abauntz, al norte de Navarra, próxima a la localidad de Arraiz, a $610 \mathrm{~m}$. de altitud. El nivel e, definido como Magdaleniense medio-superior, escaso en elementos óseos diagnósticos y con dataciones radiocarbónicas contradictorias (Utrilla 1995: 293) ha proporcionado un conjunto de varillas semicilíndricas, azagayas y espátulas con decoraciones geométricas tales como serpentiformes, escaleriformes, series en $V$, etc.(fig. 9: a-e). Por encima de este nivel, se excavó una capa denominada 2 r, que proporcionó 14 cantos con diferentes huellas antrópicas (Utrilla y Mazo, 1996a). Se destacan justamente tres de ellos con grabados de diferente temática. Los cantos 1 y 2 presentan una concepción decorativa similar, más compleja y abigarrada en el primero (fig. 9: f), que incluye diversas representaciones animales, antropomorfos, signos, convenciones como la cabra en visión frontal, etc.; todo ello dificultado en su visión por haces de lineas.Similar concepción, aunque más simple en su realización, aparece en los grabados del no 2 (fig. 9: g). El canto no 3 muestra un caballo grabado de excelente factura (1996b: 66 , fot. a y b), dibujado con gran minuciosidad y con la característica crinera de trazos cortos paralelos (fig. 9: h).

En el conjunto aragonés destaca la Cueva de Chaves, situada en Bastarás, a $663 \mathrm{~m}$. de altitud en el Pre-Pirineo oscense. El nivel 2 proporcionó 

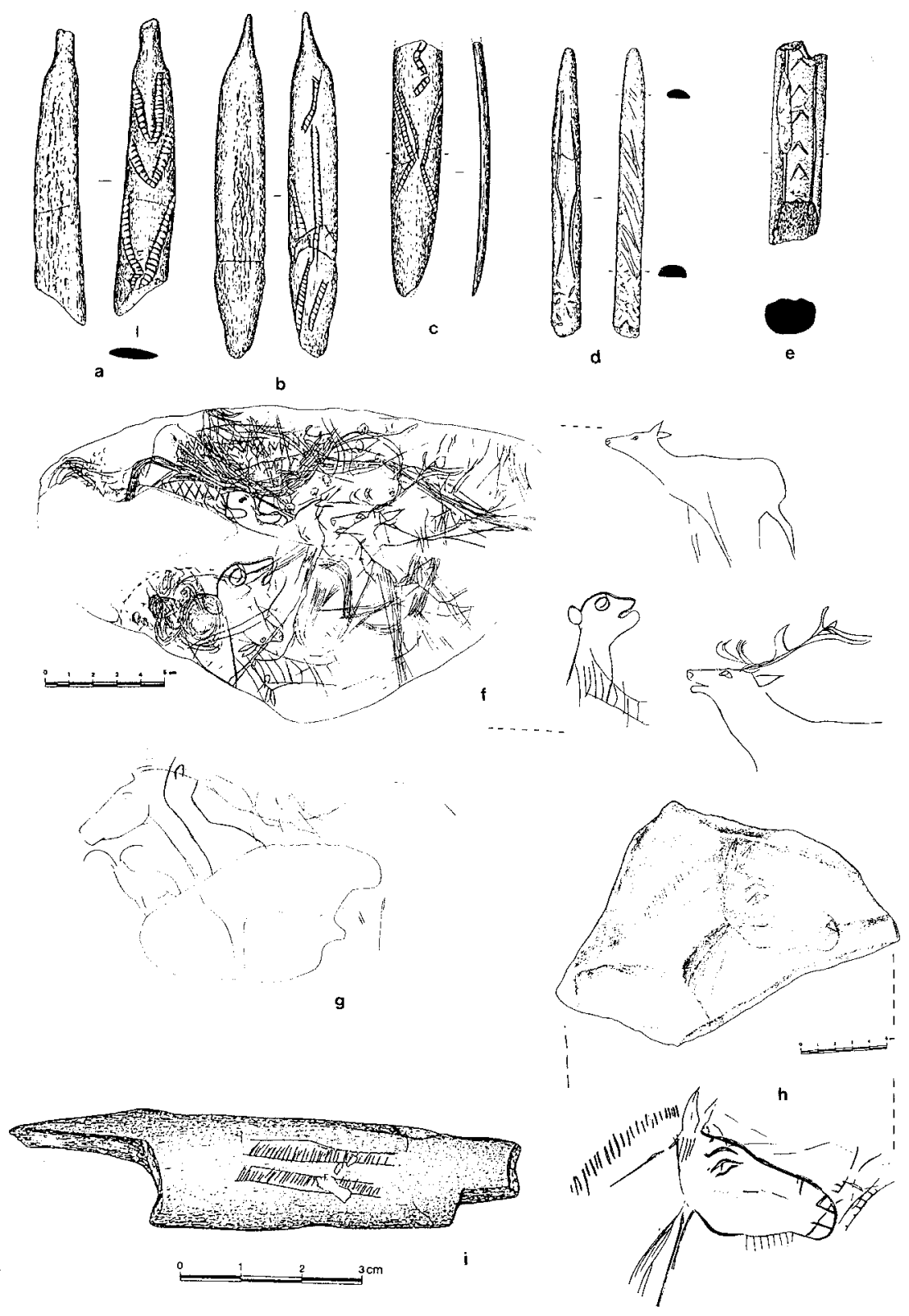

Figura 9. 
dos ocupaciones del Magdaleniense superior (Utrilla, 1989b; 1995: 283), datado entre $12.950 \pm 70 \mathrm{BP}$. y $12.020 \pm 350 \mathrm{BP}$., proporcionando un fragmento de hueso (fig. 9: i) con dos escaleriformes o pares de lineas paralelas rellenas de trazos cortos (Utrilla, 1996b: 63).

\section{LA MESETA}

Reseña historiográfica y principales hallazgos

El registro paleolítico del interior peninsular es escaso y fragmentario. No hay secuencias comparables al ámbito cantárico o mediterráneo, y el arte mueble existente se limita a dos piezas y un conjunto de plaquetas. Por tanto no existe una bibliografía de mínima entidad, en cuanto a volumen, que permita una historiografía global del área, sino comentarios puntuales. Por el contrario, el arte rupestre ha sido extraordinariamente generoso en hallazgos en la última década, destacando la cuenca del Duero con conjuntos al aire libre tan importantes como Domingo García, Siega Verde, Mazouco o Foz Côa, y la revisión y publicación con numerosas novedades de cuevas ya conocidas como La Griega (Corchón y otros, 1997). Estos hallazgos, además de otras consideraciones que se escapan a los límites de este trabajo, confirman la sospecha de que el interior peninsular no fue un despoblado durante el Paleolítico superior, y que sus restos no pueden ser vistos simplemente como una prolongación ocasional de lo cantábrico o mediterráneo. La dificultad de localizar y excavar yacimientos al aire libre producé esta situación, pero cuando se hacen prospecciones sitemáticas de yacimientos arqueológicos, como se ha hecho del arte rupestre al aire libre, aparecen también éstos (Jordá Pardo, 1993). Las cuevas con arte rupestre paleolítico no han proporcionado los yacimientos de ocupación con informacion significativa que fueran contemporáneos a las manifestaciones parietales (Balbín y Alcolea, 1994). El escaso arte rupestre existente tampoco aporta gran información por su contexto, aunque se ha publicado en excelentes trabajos monográficos, como veremos.

Sólo existe, que nosotros conozcamos, una referencia antigua a la existencia de arte mueble paleolítico en el interior peninsular. Se trata de un bastón perforado con una cabeza de cabra grabada, hallado en la Cueva del Caballón de Oña, en Burgos. Esta pieza, de la que existen noticias desde principios de siglo (Rodríguez, 1916), fue descrita por Obermaier (1925: 192), y es citada por Barandiarán (1973: 101), que revisó los materiales de la cueva, y los atribuye con probabilidad al Magdaleniense superior. 
En el Alto Valle del Jarama, Guadalajara, se han localizado una serie de yacimientos paleolíticos (Jordá Pardo, 1993) entre los que merece especial mención el denominado Jarama II. Este yacimiento proporcionó una pequeña escultura de mustélido realizada en marfil (Jordá Pardo y otros, 1988/89), identificada con un glotón (fig. 10: a), lo que da pie para establecer paralelos con el Pirineo tanto desde el punto de vista iconográfico como climático (Jordá Pardo y García Valero, 1989). Esta escultura, aunque extraida del yacimiento fuera de contexto, se ha atribuido al Magdaleniense inferior, tomando como base la existencia en el mismo de una azagaya de sección cuadrangular con grabados lineales (Adán y Jordá Pardo, 1989), único resto susceptible, junto con la mencionada escultura, de ser incluido en el capítulo mobiliar.

En las proximidades de la localidad soriana de Villalba, se localizó fuera de contexto arqueológico, a unos $1.000 \mathrm{~m}$. de altitud, una plaqueta de pizarra con diversos grabados animales (caballos, cabras y machos cabríos) y numerosas líneas (fig. 10: d); todo ello grabado con técnicas diferentes y por ambas caras (Jimeno y Fernández Moreno, 1988; Jimeno y otros, 1990). Por el estilo de las figuras animales se atribuye esta extraordinaria pieza al Solutrense superior/Magdaleniense inferior, en clara vinculación con el arte mobiliar y parietal cantábrico, aunque no falten detalles del ámbito mediterráneo. La posterior aparición de un arte rupestre al aire libre, propio y característico de la meseta, que ya hemos citado, sin duda proporciona paralelos más próximos y una personalidad propia para el arte del interior peninsular, aunque necesariamente vinculado al arte de la periferia.

La Cueva de la Hoz está situda a unos $1.050 \mathrm{~m}$. de altitud, cercana al río Salado, en la provincia de Guadalajara. Fue conocida y publicada por Cabré, en 1934, con motivo de sus trabajos en Los Casares, de la que está próxima. Sin embargo, la prospección en profundidad de las galerías interiores realizada más recientemente con motivo del estudio de sus manifestaciones parietales (Balbín y Alcolea, 1994) y la excavación practicada en el pórtico exterior, han proporcionado algunas plaquetas grabadas, de temática animalística de gran interés. El conjunto hallado hasta la fecha supera la treintena de pequeñas placas de pizarra grabadas a trazo fino, a veces sobre superficies previamente pintadas en rojo (Balbín y otros, $1995 a ; 1995 b)$. Se trata de representaciones animales, sobre todo cabezas de caballos y ciervas, aunque también aparecen bóvidos y ciervos (fig. 10: b,c). Este reparto temático no coincide con las representaciones rupestres, donde los caballos son escasos, pero muestra claros paralelos estilísticos entre lo mobiliar y lo parietal. 

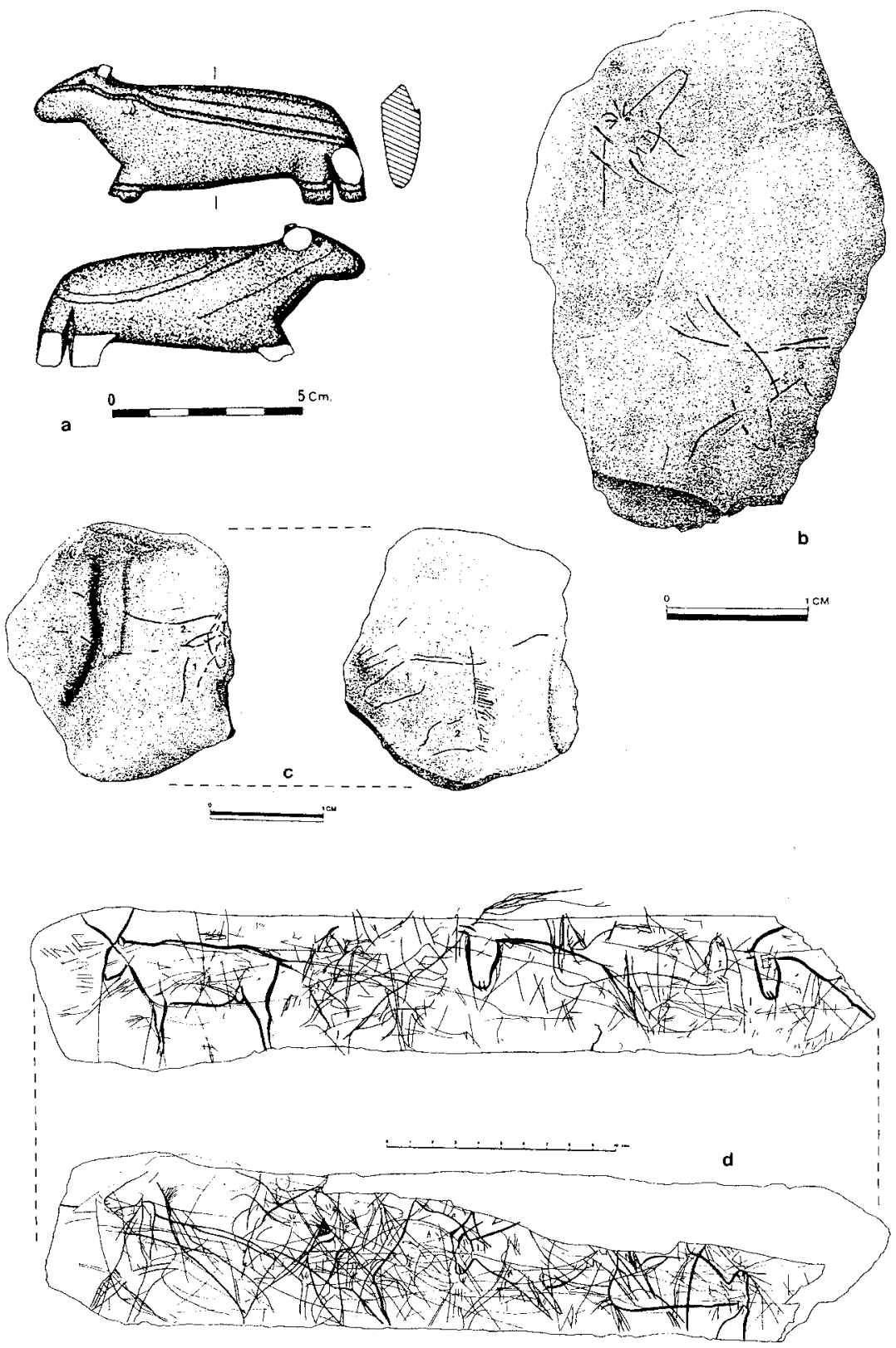

Figura 10. 
El arte mueble de la Cueva de la Hoz reúne una serie de características que le confieren extraordinaria importancia, a pesar de la humildad de sus representaciones respecto a las grandes obras cantábricas. Por primera vez aparece en el interior peninsular arte mueble en contexto. Ciertamente este contexto no es muy explícito por el momento, pero los trabajos continúan y las piezas mobiliares están donde les corresponde habitualmente: en la zona iluminada de la boca de la cueva y, excepcionalmente, en el interior decorado. Esto, unido a la aparición de los extraordinarios conjuntos rupestres al aire libre, sobre todo en la cuenca del Duero, abren una perspectiva de gran interés a la prospección de yacimientos y santuarios paleolíticos en la meseta. Además, el conjunto de plaquetas de La Hoz y la calidad de las piezas de Jarama II y Villalba indican que difícilmente se trata de obras aisladas y excepcionales, sino que debe existir una tradición con la que integrarse y suavizar el salto entre la nada y lo excepcional.

\section{EL ÁMBITO MEDITERRÁNEO}

\section{Reseña historiográfica y principales hallazgos}

Aunque el arte mueble del ámbito mediterráneo será tratado en otro trabajo de este volumen, no queremos finalizar la revisión historiográfica de los últimos años sin hacer algún comentario al respecto. Máxime cuando es en ostos últimos años cuando se han publicado verdaderos trabajos de síntesis general, han aparecido nuevos testimonios mobiliares y se ha revisado y publicado con gran acierto científico y calidad de medios la mejor colección existente para el mediterráneo y la Península Ibérica: la Cueva del Parpalló.

El arte mueble paleolítico del ámbito mediterráneo y sur de la península no presenta la cantidad de piezas y variedad de soportes y temas que hemos visto en la zona cantábrica. Es un arte realizado fundamentalmente sobre plaquetas y cántos, y sólo en contadas ocasiones sobre soportes óseos. Tiene tres núcleos fundamentales: Cataluña, comunidad valenciana y Andalucía oriental. En los últimos años se han realizado algunas síntesis que actualizan y ofrecen una alternativa al trabajo de J.Fortea (1978) que fue referencia obligada durante más de una década. Así la revisión del registro y sus atribuciones cronológicas, realizada por J.Aparicio en el ya citado congreso de Foix-Le Mas d'Azil (1987: 101-120); y la sintesis de hallazgos, con especial referencia al Parpalló y una brillante disección del concepto de provincia artística mediterránea realizada por $\mathrm{V}$. Villaverde en el número monográfico de Complutum 5 (1994b: 139-162); o la breve relación de novedades andaluzas aportada por Sanchidrián (1994: 23), 
con especial referencia a la cueva de Nerja. Respecto a estudios por períodos culturales pueden citarse los trabajos de Villaverde para el Solutrense (1994: 149-157), de Aura y Villaverde (1995: 313-340) y de A. Beltrán (1987: 101-103) para el Magdaleniense final y Epipaleolítico.

Los recientes hallazgos en Cataluña no han sido muy numerosos (FuIlola y Viñas, 1988: 123-132; Fullola y Couraud, 1984: 119-123; Fullola, Viñas y García Argüelles, 1987: 279-285), pero algunos de gran interés, como la plaqueta de Sant Gregori. En la comunidad valenciana se han hallado nuevas piezas en el Barranc y el Tossal de la Roca, Alicante (Cacho y Ripoll, 1987; Ripoll y Cacho, 1987), estando el conjunto de plaquetas grabadas del Tossal, desgraciadamente, descontextualizadas, ya que contamos con buena información para su registro (Cacho y otros, 1995); en Castellón destacan la colección de cantos grabados de de la cueva de Matutano (Olaria y otros, 1981) en un contexto magdaleniense, así como algunos hallazgos puntuales (Casabo y otros, 1991: 131-136); y sobre todo se ha realizado un estudio exaustivo de las más de 5.000 plaquetas grabadas y pintadas de la cueva valenciana del Parpalló (Villaverde, 1994a), lo que sin duda constituye una obra de refencia para todo el arte mobiliar paleolítico, además de otros estudios más breves o sobre aspectos monográficos de la colección parpallonense (Villaverde, 1988; $1990 ; 1992 ; 1994 b$ ). En Murcia se documenta un modesto conjunto magdaleniense realizado sobre hueso (Martínez Andreu, 1989). Y finalmente, en Andalucía merecen citarse los hallazgos de Cueva Ambrosio en Almería (Cacho y Ripoll, 1997: 35-62; Ripoll y Cacho, 1997: 287-293) con un prótomo de équido grabado sobre una plaqueta atribuida al Solutrense superior; el conjunto del Pirulejo, en Priego de Córdoba, entre cuyas plaquetas destaca una con un prótomo de cáprido, hallada en un nivel magdaleniense (Asquerino, 1988; 1990); finalmente la colección exhumada en la cueva malagueña de Nerja, con un lote de plaquetas con trazo estriado y restos de pintura roja, bien datadas en el Solutrense superior (Jordá, Aura y Jordá, 1990: 102-104) y los cantos, plaquetas y algunas decoraciones sobre hueso del Magdaleniense superior (Sanchidrián, 1986; Vallespí, 1990); entre los últimos destaca, por la rareza del tema, una plaqueta grabada con la figura de un pájaro, recientemente publicada (Cremades, Pellicer y Sanchidrián, 1997: 371-387).

Nuevas perspectivas en el estudio del arte mueble.

Los numerosos hallazgos que hemos descrito y se han producido en los últimos años, más los que habrán de incorporarse en un futuro próximo 
por estar actualmente en estudio y por tanto inéditos, presentan la particularidad de haber sido hallados en contextos culturales bien definidos. Esto contrasta con la descontextualización de una gran parte de las piezas antiguas, incluso con la confusión de atribuciones equívocas por aparecer entre los restos conservados en museos o colecciones algunas piezas consideradas diagnósticas de un determinado momento -fundamentalmente arpones- que se generalizaban a toda la colección. Además, comienza a abrirse paso un interesante banco de datos de fechas $C^{14} A M S$, obtenida sobre las propias piezas óseas, que sin duda aportará sorpresas en el futuro y hará variar alguna convicción actual. Por otro lado, se han descrito algunos santuarios o áreas de especiales características en algunos yacimientos, como Juyo o Tito Bustillo, que aparecen asociados a una especial abundancia de piezas mobiliares, e incluso de esculturas. En este último aspecto, es destacable la aparición en el cantábrico de obras realizadas en tres dimensiones, como ocurre con los antropomorfos de Entrefoces y El Juyo, las aves del Buxu y La Viña, la cabra de Tito BustiIlo o los relieves de Las Caldas. Además de esta técnica, han aparecido nuevos soportes (rodetes, contornos recortados) y temas antes desconocidos que ponen en estrecha relación los yacimientos del Magdaleniense medio cantábrico, sobre todo los más occidentales excavados en Asturias, con sus contemporáneos de los Pirineos. Además se han propuesto algunas figuras femeninas - venus - en Las Caldas, Tito Bustillo y $\mathrm{El}$ Buxu, aunque ciertamente todas ellas poco explícitas. Finalmente, el cambio que paulatinamente se ha ido produciendo en la explicación del desarrollo secuencial del Magdaleniense, la crisis en la tradicional confianza en los fósiles directores como elemento de prueba, la datación y la aparición de nuevas piezas en contexto, han arrojado serias dudas sobre la concepción rígida de la evolución estilística, que identifica determinados temas con cronologías o definiciones culturales específicas. La importancia de este último punto merece dedicarle algún comentario más extenso.

Desde la década de los sesenta se ha asistido a un proceso desmitificador de las fases magdalenienses de Breuil; primeramente en Francia y después en el Cantábrico se ha ido admitiendo la idea de facies magdalenienses frente a la visión lineal y evolutiva de fases continuas, que por otra parte Breuil no pretendió. De esta manera se ha asentado la idea del poligenismo y autoctonismo en el origen del Magdaleniense (Utrilla, 1984-85: 90; Corchón, 84-85: 76), desmitificando las clasificaciones rígidas y aceptando que "cada región, e incluso cada cueva, parece tener su propia tradición», según P. Utrilla. No obstante, algo parece salvarse de las tesis tradicionales: existe un magdaleniense sin arpones y otro con arpones; este último es el verdadero Magdaleniense, que se configura en lo que se llamó Magdaleniense 
IV con los protoarpones y se desarrolla hasta la aparición del Aziliense, con nuevos tipos aplanados (González Echegaray y Barandiarán, 1981; Utrilla, 1984-85; González Sainz 1989a y 1989b, 1995; etc.). La primera objeción al nuevo esquema rígido es la existencia de niveles del Magdaleniense medio sin protoarpones, hasta el momento, en La Viña y Las Caldas, paralelizables con la más brillante tradición del Magdaleniense IV pirenaico. Además del problema del origen de esta facies, o como queramos llamarla, en el occidente cantábrico. Sin embargo, esto excede el objetivo de este artículo, por lo que sólo queremos apuntarlo como base a otros argumentos.

Las recientes dataciones AMS de Tito Bustillo insisten en situar por debajo del 14.000 BP. el complejo inferior, donde ha aparecido un arpón (Moure, 1997), corroborando series de dataciones anteriores. Esta alta datación para un nivel con arpones no es frecuente, pero tampoco única. El reciente trabajo de Corchón sobre las dataciones absolutas magdalenienses muestra igualmente el carácter sincrónico de niveles con y sin arpones (Cochón, 1995c). Es decir, aunque la distinción presencia/ausencia de arpones siga siendo pertinente en sentido cultural, su significación cronológica ha perdido la anterior rigidez, ya que el arpón constituía el fósil director emblemático del mundo magdaleniense superior.

La aparición en 1990 de una tibia de ciervo decorada con tres cabezas de cierva en el nivel 3c, Magdaleniense inferior facies Juyo, de la cueva de La Güelga, enlaza con la desmitificación que estamos trazando (Menéndez y Martínez, 1991-92). En esta pieza, que ya hemos mencionado antes (fig. $5:$ b) encontramos una figura - cierva A-que encaja perfectamente con los modelos y convenciones descritos para el Magdaleniense inferior, de dibujo rígido y raíz lineal, en terminología de Apellániz; en otro campo decorativo de la misma pieza se realizaron otras dos cabezas de cierva - B y $\mathrm{C}$ - que responden a convenciones y tipo de dibujo blando, de raíz pictórica, que caracteriza al Magdaleniense superior. Como ambos tipos de ciervas se realizaron a la vez, con el hueso aún fresco, debemos convenir la coexistencia de estilos tradicionalmente asignados al Magdaleniense con y sin arpones respectivamente. En el mismo nivel aparece una representación de cabra en visión frontal, tema no exclusivo pero muy característico del Magdaleniense con arpones. Igualmente, algunas plaquetas grabadas con figuras animales en Tito Bustillo, localizadas en niveles con arpones, pueden paralelizarse con otras del Magdaleniense inferior de Altamira o Castillo. $Y$ así podrían citarse algunos ejemplos más. En resumen, parece que también se desdibuja esa frontera nítida que separaba el Magdaleniense con y sin arpones; como también se diluye la adscripción rígida de un estilo o una convención determinada a una cronología específica. Al igual que cada región e incluso cada cueva "parece tener su 
propia tradición» respecto a las facies, también sin duda la tiene respecto a las manifestaciones artísticas. La anterior visión de evolucionismo unilineal era demasiado cómoda para que pudiera ser cierta.

\section{BIBLIOGRAFIA}

AdÁn Álvarez, G., 1998: De la caza al útil: la industria ósea del tardiglaciar en Asturias. Consejería de Cultura. Principado de Asturias.

adán Álvarez, G.; García Valero, M.A.; Jordá Pardo, J.F. y Sánchez Chillón, B., 1989: Jarama II, nouveau gisement Magdalénien avec art mobilier de la Meseta Castellana (Guadalajara, Espagne). Préhistoire Ariègeoise, t. XLIV: 97-120.

Adán Álvarez, G. y Jordá PARdo, J.F., 1989: Industrias óseas del paleolítico y postpaleolítico pirenaico en relación con los nuevos hallazgos de Jarama II (Guadalajara). Espacio, Tiempo y Forma, Serie I, 2: 109-130. UNED. Madrid.

AlmaGRo, M., 1981: Los grabados de trazo múltiple en el arte cuaternario español. Altamira Symposium, 27-70.

AltunA, J., y Merino, J.M., 1984: El yacimiento prehistórico de la Cueva de Ekain (Deba. Guipúzcoa). Sociedad de Estudios Vascos.

ALONSO SILIO, R., 1986: El modelado interior de los grabados rupestres paleolíticos del Norte de la Península. En Estudio de Arte Paleolítico, 133-264. Centro de Inv. y Museo de Altamira, 15. Madrid.

Aparicio Pérez, J., 1987: Chronologie de l'Art Mobilier Paléolithique dans L'Espagne Méditerranéenne. En L'Art des objets au Paléolithique. T. I: 101-120. Foix-le Mas d'Azil.

APELLÁNIZ, J.M., 1988: La plaquette à chevaux hypertrophiques de Lumentxa (Biscaye) et les styles du Magdalénien supérieur/final dans le Pays Basque. Munibe, 40: 9-14. San Sebastián.

APELLÁNIZ, J.M., 1989: Analyse de la rectification comme mecanisme de la méthode de détermination de l'auteur dans l'iconographie paléolithique. Les graveurs de la plaquette du Magdalénien VI de Ekain (Deva. Guipúzcoa, Pays Basque, Espagne). L'Anthropologie, 93, 2: 463-474.

ApELLÁNIZ, J.M., 1991: Modelo de análisis de la autoría en el arte figurativo del Paleolítico. Cuadernos de Arequeología de Deusto, 13. Bilbao.

ArmendÁriz, A., 1991. Antón Koba. Arkeoikuska, 91: 98-100

ArmendÁRIZ, A., 1992. Antón Koba. Arkeoikuska, 92: 190-193.

Arribas, J.L., y Berganza, E., 1988a: Placa de hueso decorada de Laminak II (Berriatua, Bizkaia). Munibe, 40: 15-19. San Sebastián.

ArriBAS, J.L., y BerganzA, E., 1988b: Laminak II. Arkeoikuska, 88: 81-83.

Asquerino, M.D., 1988: Avance sobre el yacimiento magdaleniense del Pirulejo (Priego de Córdoba). Estudios de Prehistoria Cordobesa, 4: 59-68

Asouerino, M.D., 1990: Informe-memoria sobre la campaña de excavaciones de 1987 en la Cueva de Los Mármoles (Priego de Córdoba). Anuario Arqueológico de Andalucía 1987/II Actividades sitemáticas, 375-379.

Aura Tortosa, J.E., 1986: Algunos objetos de la Cueva del Pendo depositados en Valencia. Trabajos de Prehistoria, 43: 187-194.

AuRA, J.E. y VILLAVERDE, V., 1995: Paleolítico Superior final y Epipaleolítico antiguo en la España Mediterränea (18.000-9.000 B.P.). En El final del Paleolítico Cantábrico, Moure y González (edit): 313-340. Santander.

Balbín Berhman, R., y Alcolea, J.J., 1994: Arte paleolítico de la meseta española. Complutum, 5: 97-138. Madrid.

Balbin Berhiman, R.; Alcolea, J.J. y Cruz, L.A., 1995a: Las placas decoradas de la Cueva de la Hoz (Sta. $M^{a}$ del Espino, Guadalajara): un ejemplo de arte mobiliar paleolítico en la meseta castellana. $1^{\circ}$ Congresso de Arqueologia peninsular. Porto, 1993. Actas Vol. VII. Trabalhos de Antropologia e Etnologia, XXXV: 49-63.

Balbín Berhman, R.; Alcolea, J.J.; Moreno, F. y Cruz, L. A., 1995b: Investigaciones arqueológicas en la Cueva de la Hoz (Santa del Espino, Guadalajara). Una visión de conjunto actualizada. Arqueología en Guadalajara, 38-53. 
BALDEÓN, A., 1984: Industria ósea del yacimiento de Ekain. En Altuna y Merino, 1984: 189-210. Barandiarán, I., 1973a: Arte mueble del Paleolítico cantábrico. Monog. XIV. Univ. Zaragoza.

BARANDIARÁN, I., 1973b: Algunas convenciones de representación en las figuras animales del arte paleolítico. Santander Symposium, 345-381.

BARANDIARÁN, I., 1984a: Utilización del espacio y proceso gráfico en el arte mueble paleolítico. En Scripta Praehistorica F.Jorda Oblata: 113-161. Salamanca.

BARANDIARÁN, I., 1984b: Signos asociados a hocicos de animales. VELEIA, 1: 7-24. Vitoria

BARANDIARÁN, I. y otros, 1985: Excavaciones en la cueva del Juyo. Centro de Investigación y Museo de Altamira, 14. Ministerio de Cultura.

BARANDIARÁN, I., 1988a: Constantes y variabilidad del arte portátil magdaleniense en la vertiente cantábrica. Veleia, 5: 45-60.

BARANDIARÁN, I., 1988b: Datation C14 de l'art mobilier magdalénien cantabrique. Bulletin de la Societé Préhistorique de l'Ariege, 43: 63-84.

BARANDIARÁN, I., 1989: El Magdaleniense en Asturias, Cantabria y País Vasco: constantes y variabilidad del arte portátil. En Le Magdalénien en Europe. Actes du Colloque de Mayence 1987, ERAULT, 38: 379- 396.

BARANDIARÁN, I., 1993: El lobo feroz: La vacuidad de un cuento magdaleniense. VELEIA, 10: 7 37. Vitoria.

Barandiarán, 1., 1994: Arte mueble paleolítico cantábrico: una visión de síntesis en 1994. En Chapa y Menéndez (edit.), 1994: 45-79. Madrid.

BaRANDIARÁN, I., 1996a: Art mobilier cantabrique: styles et tecniques. En L'art préhistorique des Pyrénées, Catálogo de la exposición del Musée des Antiquités nationales (Saint-Germainen-Laye), pp. 88-121.

BARANDIARÁN, l., 1996b: El arte mobiliar del hombre fósil cantábrico. En Moure, 1996a: 345369. Santander.

Barandiatán, I.; Freeman, L.G.; González Echegaray, J., y Klein, R.G., 1985: Excavaciones en la Cueva del Juyo. Centro de Investigación y Museo de Altamira, 14. $\mathrm{M}^{2}$ de Cultura. Madrid.

Barandiarán, 1., y González Echegaray, J., 1979: Arte mueble de la Cueva del Rascaño (Santander): Campaña de 1974. Quartar, 29-30: 123-132.

Barandiarán, J.M. DE y ALTunA, J., 1977: Excavaciones en Ekain (Memoria de las campañas 1969-1975). Munibe, 29: 3-58. San Sebastián.

BeltRÁN, A., 1987: Réflexions sur L'Art mobilier magdalénien final et azilien, et le supposé hiatus entre l'art paléolithique, l'art mésolithique et l'art pariétal du levant espagnol. En L'Art des objets au Paléolithique, t. 2: 101-103. Foix-le Mas d'Azil.

Berganza, E. y ArRibas, J.L., 1988: Laminak II. Arkeoikuska, 88: 81-83.

Bernaldo de Quirós, F.; GutiérRez Sáez, C.; Heras, C. de las; Laguera, M.A.; Pelayo, M.; PuMAREJO, P., Y UZQUIANO, P., 1992: Nouvelles donnes sur la transition magdalénien supérieurAzilien. La Grotte de «La Pila» (Cantabria, Espagne). En Le peuplement magdalénien, Colloque de Chancelade: 259-269.

Cabrera Valdés, V., y Giménez de la Rosa, M.: Sobre la industria ósea de Altamira. Espacio, Tiempo y Forma, Serie I, t. IV: 93-110. UNED. Madrid.

CACHO QUESADA, C., y RIPOLL LOPEZ, S., 1987: Nuevas piezas de artre mueble en el Mediterráneo español. Trabajos de Prehistoria, 44: 35-62.

Cacho, C.; Fumanal, M.P.; López, P.; López, J.A.; Pérez Ripoll, M.; Martínez Valle, R.; Uzquiano, P.; Arnanz, A.; Sánchez Marco, A.; Sevilla, P.; Morales, A.; Roselló, E.; GarralDA, M.D., y García CarRiLlo, M., 1995: El Tossal de la Roca (Vall d'Alcalá, Alicante). Reconstrucción paleoambiental y cultural de la transición del Tardiglaciar al Holoceno inicial. Recerques del Museu d'Alcoi, IV: 11-101.

Casado, J.; Granell, E.; Portell, E.; Ullola, P., 1991: Nueva pieza de arte mueble paleolítico en la provincia de Castellón. Saguntum-PLAV, 24: 131-136.

CONKEY, M.W., 1980: The identification of Prehistoric Hunter-Gatherer Aggregation Sites; the case of Altamira. Current Antropology, 21: 609-630.

CONKEY, M.W., 1990: L'art mobilier et l'établissement de géographies sociales. En L'Art des objets au Paléolithique, 2: 163-172. Colloque International, Foix-le Mas d'Azil.

CONKEY, M., 1992: Les sites d'agregation et la répartition de l'art mobilier, ou: y a-t-il des sites d'agregation magdaléniens? En Le peuplement magdalénien, Colloque de Chancelade: 19 25.

CORCHón, M.̊S., 1981: La Cueva de Las Caldas. Excavaciones Arqueológicas en España, 115. Madrid. 
CORCHÓN, M. ${ }^{a}$ S., 1984-85: Problemas actuales en la interpretación de las industrias del Paleolítico superior cantábrico: algunas reflexiones. Zephyrus, 84-85: 51-85. Salamanca.

CORCHÓN, M.'S., 1986: Arte mueble paleolítico cantábrico: contexto y análisis interno. Centro de Inv. y Museo de Altamira. Mon. 16. M․ Cultura. Madrid.

CORCHÓN, M. ${ }^{\Xi}$ S., 1987: Los relieves en el arte mueble paleolítico cantábrico. Ars Praehistorica 5-6: $31-48$.

CORCHÓN, M. $\stackrel{a}{ }$ S., 1990a:La cueva de Las Caldas (Priorio, Oviedo). Investigaciones efectuadas entre 1980 y 1986. Excavaciones Arqueológicas en Asturias, 1983-1986: 37-53. Junta del Principado de Asturias.

CORCHÓN, M.․․, 1990b: Iconografía de las representaciones antropomórficas paleolíticas: a propósito de la «Venus» magdaleniense de Las Caldas (Asturias). Zephyrus, 43: 17-37. Salamanca.

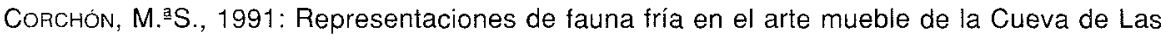
Caldas (Asturias, España). Significación e implicaciones en el Arte Parietal. Zephyrus, XLIV-XLV. 35-64. Salamanca.

CORCHÓn, M. a-S., 1992a: La cueva de Las Caldas (Priorio, Oviedo). Il Investigaciones efectuadas entre 1987 y 1990. Excavaciones Arqueológicas en Asturias, 1987-1990: 33-47. Junta del Principado de Asturias.

CORCHON, M. ${ }^{2}$ S., 1992b: Representaciones de fauna fria en el Arte mueble de la cueva de Las Caldas (Astutias.España). Significación e implicaciones en el arte parietal. Zephyrus, XLIVXLV: 35-64. Salamanca

CORCHÓN, M. ${ }^{2}$ S., 1993: El Magdaleniense con triángulos de Las Caldas (Asturias. españa). Nuevos datos para la definición del Magdaleniense inferior cantábrico. Zephyrus, XLVI: 77 94. Salamanca.

CORCHÓN, M.․․, 1994a: Le Solutréen de la région cantabrique. Relations avec le Portugal. En Le Solutréen en la Péninsule ibérique: 39-74. Musée départamental de Solutré.

CORCHÓN, M. ${ }^{2}$ S., 1994b: Últimos hallazgos y nuevas interpretaciones del arte mueble paleolítico en el occidente asturiano. En Chapa y Menéndez (edit.), 1994: 235-264. Madrid.

CORCHón, M. as., 1994c: Arte mobiliar e industria ósea solutrense en Is cornisa cantábrica, Férbedes, 1: 131-148. Villalba. Lugo.

CORCHÓN, M. aS., 1995a: La Cueva de Las Caldas (Priorio,Oviedo). Ill. Resultados preliminares de las excavaciones (Campañas de 1991-1994). Excavaciones arqueológicas en Asturias, 1991-1994: 45-60. Consejería de Cultura. Oviedo.

CORCHÓN, M. ${ }^{a S}$., 1995b: El Magdaleniense medio cantábrico: nuevas evidencias. En Moure y González, 1995: 119-158. Santander.

CORCHÓN, M. ${ }^{\text {SS., }}$ 1995c: Reflexiones acerca de la cronología del Magdaleniense cantábrico. Las dataciones $14 \mathrm{C}$ de la Cueva de Las Caldas. Zephyrus, XLVIII: 3-19. Salamanca.

CORCHÓN, M.'S., 1997: La corniche cantabrique entre 15.000 et 13.000 ans BP.: La perspective donnée par l'art mobilier. L'Anthropologie, t. 101, $\mathrm{n}^{\circ}$ 1: 114-143.

CREMADES, M., 1994: L'art mobilier paléolithique: analyse des procedés technologiques. En Chapa y Menéndez (edit), 1994: 369-384. Madrid.

Cremades, M.; Pellicer, M.; SAnchidrián, J.L., 1997: Nouvelles figurations d'oiseaux de l'art mobilier paléolithique franco-español. PALEO, 9: 371-387.

ChAPA, T., y MENÉNDEZ, M. (eds..), 1994: Arte Paleolítico. Complutum, 5. Madrid.

Fernández IBÁÑez, C; Giménez de la Rosa, M.; Muñoz Fernández, E.: 1993: Un «bastón perforado" procedente la caverna del Castillo (Puente Viesgo, Cantabria). Boletín Cántabro de Espeleología, 9: 32- 34. Santander.

Fernández-TresguerRes, J., 1980: El Aziliense en las provincias de Asturias y Santander. Centro de Investigación y Museo de Altamira, 2. $\mathrm{M}^{0}$ de Cultura. Madrid.

Fernández-Tresguerres, J., 1990: Arpones decorados azilienses. Zephyrus, XLIII: 47-51. Salamanca.

Fernández-TresguerRes, J., 1994: El arte aziliense. En Chapa y Menéndez (edit.), 1994: 81-95. Madrid.

Fernández-Tresguerres, J.; Junceda Quintana, F., 1992: Informe sobre las campañas de excavación realizadas en la cueva de Los Azules entre 1986 y 1990 . Excavaciones arqueológicas en Asturias, 1987-1990: 89-94. Consejería de Cultura. Oviedo.

Fernández-Tresguerres, J.; Rodriguez Fernández, J.J.;1990: La Cueva de Los Azules (Cangas de Onís). Excavaciones arqueológicas en Asturias, 1983-1986: 129-133. Consejería de Cultura. Oviedo. 
Fortea, F.J., 1978: Arte Paleolítico del Mediterráneo español. Trabajos de Prehistoria, 35: 99149.

ForTEA, J., 1983: Perfiles recortados del Nalón Medio (Asturias). Homenaje al profesor M. Almagro Basch, l: 343-353.

FORTEA, J., 1989: El Magdaleniense medio en Asturias,Cantabria y Pais Vasco. En Le Magdalénien en Europe. La structuration du Magdalénien. Actes du Colloque du Mayence, 1987, ERAUL, 38: 419-440. Liège.

FORTEA, J., 1990: Abrigo de la Viña. Informe de las campañas 1980-1986. Excavaciones arqueológicas en Asturias 1983-86: 55-68. Junta del Principado de Asturias.

ForteA, J., 1992: Abrigo de la Viña. Informe de las campañas de 1987 a 1990. Excavaciones Arqueológicas en Asturias, 1987-1990: 19-28. Junta del Principado de Asturias.

FORTEA, J., 1994: Los "santuarios" exteriores en el Paleolítico cantábrico. En T. Chapa y M. Menéndez (eds.), Arte Paleolítico, Complutum, 5: 203-220. Madrid.

FORTEA, J., 1995: Abrigo de la Viña. Informe y primera valoración de las campañas 1991 a 1994. Excavaciones Arqueológicas en Asturias, 1991-1994: 19-32. Junta del Principado de Asturias.

Fortea, J.; Corchón, M.ås.; González Morales, M.; Rodriguez Asensio, A.; Hoyos, M.; Laville, H.; Dupre, M., y Fernández-TResguerres, J., 1990: Travaux récents dans les vallées du Nalon et du Sella. En L'Art des objets au Paléolithique, I: 219-246 Colloque International, Foix-le Mas d'Azil.

Fortea, J.; Rasilia, M. De La, y Rodríguez Otero, V., 1990: Sobre un rodete perforado magdaleniense de Llonín (Asturias). Archivo de Prehistoria Levantina, XX: 95-108. Valencia.

Fortea, J.; Rasilla, M. De LA, y Rodriguez Otero, V., 1992: La Gueva de Llonín (Llonín, Peñamellera, Asturias). Campañas de 1987 a 1990. Excavaciones Arqueológicas en Asturias, 1987-90: 9-18. Junta del Principado. Asturias.

Fortea, J.; Rasilla, M. De la, y Rodríguez Otero, V., 1995: La Cueva de Llonín (Llonín, Peñamellera, Asturias). Campañas de 1991 a 1994. Excavaciones Arqueológicas en Asturias, 1991-94: 33-43. Junta del Principado. Asturias.

Freeman, L.G., 1988: The stratigraphic sequence at Altamira, 1880., 1981. Espacio, Tiempo y Forma, Serie I, t.l: 149-163. UNED. Madrid.

Freeman, L., y González Echegaray, J., 1982: Magdalenien mobile art from El Juyo, Ars Praehistorica, 1: 161-167.

Fullola, J.M. y y COURAud, C., 1984: Le galet peint de l'abri du Filador (Catalogne, Espagne). L'Amthopologie, 88: 119-123.

FUlloLA, J.M ${ }^{\mathrm{a}}$, VINAS, R., 1988: Derniéres découvertes dans l'art prehistorique de Catalogne (Espagne). L'Anthropolgie, 92: 123-132.

FulLoLA, J.M. ${ }^{-}$; VINAS, R., y GARCIA ARGüELLES, P., 1986: La plaque en ardoise gravée de l'Abri de El Filador (Catalogne, Espagne). Cahiers ligures de préhistoire et de protohistoire, 3 : 147-157.

Fullola, J.M. ${ }^{\text {a }}$; ViñAs, R., y Garcia ARgüelles, P., 1987: La nouvelle plaquete gravée de Sant Gregori (Catalogne, Espagne). L'Art des objets au Paléolithique, t. I: 1: 279-285. Foix-le Mas d'Azil.

GARCíA GUINEA, M.A., 1986: Los bastones magdalenienses en Cantabria. El hallazgo de Cualventi (Oreña). C.A. a la UNED de Cantabria, lesción inaugural del curso 1986-87, Santander.

Gómez Tabanera, J.M., 1980: La Caza en la Prehistoria. Edit.l stmo.

GONZÁLEZ ECHEGARAY, J., 1984: Reflexiones sobre el momento actual en la investigación del Paleolítico superior cantábrico. En Scripta Praehistorica F. Jorda Oblata, 259-270. Salamanca.

GonzAlez Echegaray, J., 1988: El Magdaleniense de Altamira. Espacio, Tiempo y Forma, Serie I, t. I: 165-175. UNED. Madrid.

González Echegaray, J., y Freeman, L. G., 1981: La Máscara del Santuario de la Cueva del Juyo. Altamira Symposium, 251-265. Madrid.

González Echegaray, J., y Barandiarán, I., 1981: el Paleolítico Superior de la Cueva del Rascaño (Santander). Centro de Investigación y Museo de Altamira, 3. Ministerior de Cultura.

González Echegaray, J.; García, M.A., y BeGines, A., 1963: Cueva de La Chora. Excavaciones Arqueológicas en España, 26. Madrid.

Gonzál.ez Echegaray, J., y otros, 1980: El yacimiento de la Cueva del Pendo. Bibliotheca Praehistorica Hispana, 17, Madrid.

GonzÁlez MoRAles, M.R., 1983: Fragmento de placa ósea decorada del Magdaleniense final de la Cueva de La Riera (Asturias). Homenaje al Prof. Martín Almagro Basch, 1: 355-361. Madrid. 
González Morales, M.R., 1990: El abrigo de Entrefoces (1980-1983). Excavaciones Arqueológicas en Asturias, 1983-86: 49-52. Junta del Principado. Asturias.

GonzÁlez Morales, M.R., 1992: Excavaciones en el abrigo de Entrefoces. Campaña de 1987 y 1989. Excavaciones Arqueológicas en Asturias, 1987-90: 29-36. Junta del Principado. Asturias.

GonzÁlez SáInZ, C., 1982: Un colgante decorado de Cueva Morín (Santander). Reflexiones sobre un tema decorativo del Paleolítico superior. Ars Praehistorica, 1: 151-159

GONZÁLEZ SÁINZ, C., 1984: Sobre una plaqueta grabada magdaleniense de la Cueva de Urtiaga. Munibe, 36: 11-17. San Sebastián.

GoNZÁLEZ SÁINZ, C., 1989a: El Magdaleniense superior-final en la región cantábrica. Edit. Tantín. Santander.

GonZÁlez SÁlNZ, C., 1989b: Notas sobre el Magdaleniense superior-final de la región cantábrica. En Le Magdalénien en Europe. La structuration du Magdalénien. ERAUL, 38: 441-455. Liège.

GonZÁLEZ SÁINZ, C., 1992: Algunos paralelos entre el arte mobiliar y el rupestre. Una revisión crítica. En Repensar Altamira (M. Fernández Miranda, dir). UIMP, Santander.

GonzÁlez SÁINZ, C., 1993: En torno a los paralelos entre el arte mobiliar y el rupestre. VELEIA, 10: 39- 56. Vitoria.

GoNZÁLEZ SÁINZ, C., 1995: 13.000-11.000 BP. El final de la época magdaleniense en la región cantábrica. En Moure y González Sáinz Edit., 1995: 159-198. Santander.

GonZÁlez SÁinZ, C., 1996: Chasseurs de cerfs et de bouquetins sur la côte cantabrique. En L'art préhistorique des Pyrénées, Catálogo de la exposición del Musée des Antiquités nationales (Saint- Germain-en-Laye), pp. 132-139

GONZÁlEZ SÁINZ, C.; MONTES BARQUÍN,R.; MUÑOZ FERNÁNDEZ,E., 1994: La Cueva de Sovilla (San Felices de Buelna. Cantabria). Zephyrus, XLVI: 7-36. Salamanca.

GutiérRez, C.; De las Heras, C., y Bernaldo de Quirós, F., 1986/1987: Arte mueble figurativo de la Cueva de la Pila (Cuchía, Cantabria). Ars Praehistorica, 5-6: 221-234.

Hoyos, M., 1995: Cronoestratigrafía del Tardiglaciar en la región cantábrica. En Moure y González, 1995: 15-76. Santander.

HoYOS, M., y LAVILLE, H., 1982: Nuevas aportaciones sobre estratigrafía y sedimentología de los depósitos del Paleolítico Superior de la Cueva del Pendo: sus implicaciones. Zephyrus, 34-35: 286-293.

Hoyos Gómez, M.; Martínez Navarrete, M.․․; Chapa Brunet, T.; Castaños, P., y Sanchiz, F.B., 1980: La Cueva de la Paloma. Excavaciones Arqueológicas en España, 116. Madrid.

Jimeno, A., y FERNÁNDEZ MORENO, J.J., 1988: Una placa de arte mueble paleolítico en la provincia de Soria. Trabajos de Prehistoria, 45: 235-241.

jimeno, A.; Fernández Moreno, J.J.; Gómez Barrera, J.A., y Galindo, M.P., 1990: Arte paleolítico en la provincia de Soria: la placa de Villalba. Numantia, Ill: 9-50.

Jordá PARdo, J.F.; Aura Tortosa, E., y JoRdÁ Cerdá, F., 1990: El límite Pleistoceno-Holoceno en el yacimiento de la Cueva de Nerja (Málaga). Geogaceta, 8: 102-104.

JORDÁ PARDO, J.F., 1993: El poblamiento prehistórico en el sector sur-oriental del Sistema Central peninsular (Alto Valle del Jarama,Guadalajara, España). $1^{\circ}$ Congreso de Arqueologóa Peninsular. Trabalhos de Antropologia e Etnologia. Vol. 33 (3-4): 99-113. Porto.

Jordá PARDO, J.F., y GARCíA VALERO, M.A., 1989: Las representaciones de glotón (Gulo gulo L.) en el Arte Paleolítico pirenaico y nuevo hallazgo de Arte Mueble en el Alto Valle del Jarama (Guadalajara). Espacio, Tiempo y Forma. Serie I, 2: 89-107. UNED. Madrid.

Jordá Pardo, J.F.; Garcia Valero, M.A.; Adán Álvarez, G., y Sánchez Chillón, B., 1988/89: Una nueva pieza de Arte Mueble magdaleniense: el glotón de la cueva de Jarama II. (Valdesotos, Guadalajara). Ars Praehistorica, VII-VIII: 107-122.

Lagüera García, M.A., 1991: La tipología del utillaje lítico del yacimiento de La Pila (Cuchía, Mogro, Cantabria). Espacio, Tiempo y Forma, Serie I, t. IV:37-92. UNED. Madrid.

Lawson, A.L. Edit.., 1991: Essays in Palaeolithic Art. Proceedings of the Prehistoric Society, vol. 57, Part 1. Londres.

Lerol-Gourhan, A., 1965: Préhistoire de l'Art Occidental. París.

MARTínez AndREu, M., 1989: El Magdaleniense superior en la costa de Murcia. Editora regional de Murcia. Colección Documentos, 2.

MARTinez, A., y MenÉNDEZ, M., 1995: Arte mueble magdaleniense de la Cueva de La Güeiga, Cangas de Onís, Asturias. Congreso de Arqueología Peninsular. Porto. Actas VI: 17-25. Trabalhos de Antropología e Etnología. Vol. 35 (2). 
MenÉndez, M., 1983: La Cueva del Buxu. Boletín del Instituto de Estudios Asturianos, 111: 143-185. Oviedo

Menéndez, M., 1984: La Cueva del Buxu. B.I.D.E.A. 112: 755-801. Oviedo.

MenÉnDEZ, M., 1990: La Cueva del Buxu. Excavaciones, Campaña de 1986. Excavaciones Ar queológicas en Asturias, 1983-1986: 87-91. Junta del Principado de Asturias, Oviedo.

MENÉNDEZ, M., 1992: Excavaciones arqueológicas en la Cueva del Buxu (Cardes, Cangas de Onís). Excavaciones arqueológicas en Asturias, 1987-1990: 69-74. Consejería de Educación y Cultura. Oviedo.

MENÉNDEZ, M., 1994: Arte rupestre y arte mueble paleolítico: relaciones. En Chapa y Menéndez (edit.) 1944: 343-355. Madrid.

MenÉNDEZ, M., y GaRCíA, E., 1997: La Cueva de la Güelga (Asturias): Arte mueble y territorialidad en el Magdaleniense cantábrico. XXXIV Cong. Arqueológico Nacional. Cartagena, 1997 (en prensa).

MENÉNDEZ, M., y MARTínez, A., 1991-92: Una tibia con ciervas grabadas de la Cueva de la Güelga, Cangas de Onís, Asturias. Zephyrus, 44-45: 65-76.

MenÉnDEZ, M., y MARTínez, A., 1992: Excavaciones arqueológicas en la Cueva de la Güelga. Campañas de 1989-1990. Excavaciones Arqueológicas en Asturias, 1987-1990. Consejería de Educación y Cultura. Oviedo.

MENÉNDEZ, M., y OcIO, P., 1997: Novedades en el arte mueble y su relación con el arte rupestre en la cueva del Buxu (Asturias). I/ Congreso de Arqueología Peninsular. pp. 173-184, Zamora. 1997.

MenÉndez, M., y OlavarRI, E., 1983: Una pieza singular de arte mueble de la Cueva del Buxu (Asturias). Homenaje al Prof. Martín Almagro Basch, 1: 319-329.

MenÉnDez García, 1994: Consideraciones en torno a los llamados «bastones de mando». Zephyrus, XLVII: 333.342. Salamanca.

Moure, A., 1975. Excavaciones Arqueológicas en la cueva de Tito Bustillo (Ribadesella, Asturias). Inst. de Estudios Asturianos. Oviedo.

Moure, A., 1974: Bastón de mando descubierto en el Magdaleniense superior de la cueva de Tito Bustillo. B.I.D.E.A., 84: 843-853.

Moure, A., 1975. Excavaciones Arqueológicas en la cueva de Tito Bustillo (Ribadesella, Asturias). Inst. de Estudios Asturianos. Oviedo.

Moure, A., 1976: Excavaciones realizadas en la cueva de Tito Bustillo (Ribadesella, Asturias). Noticiario Arqueológico Hispano, 5: 65-71.

Moure, A., 1979a: Una plaqueta grabada del Magdaleniense superior de Tito Bustillo. Caesaraugusta, 49, 50: 43-54.

Moure, A., 1979b: Le Magdalenien Superior de la Grotte de Tito Bustillo (Asturias, Espagne). Colloque International 271 "La Fin des Temps Glaciaires" (Talence, 1977), I: 737-743.

Moure, A., 1982a: Placas grabadas de la cueva de Tito Bustillo. Studia Archaeologica, 69. Valladolid.

Moure, A., 1982b: Espátula decorada procedente del Magdaleniense de Tito Bustillo. BIDEA, 107: $667-681$.

MOURE, A., 1982c: Nuevas placas con representaciones de animales en el Magdaleniense cantábrico. Boletín del Seminario de Estudios de Arte y Arqueología, XLVIII: 5-24.

MOURE, A., 1983: Escultura magdaleniense descubierta en la cueva de Tito Bustillo. Ars Praehistorica, 2: 169-176

Moure, A., 1984: Representaciones femeninas en el arte mueble de la cueva de Tito Bustillo. Bol. del M.A.N., 2: 69-76. Madrid.

Moure, A., 1985: Nouveautés dans l'art mobilier figuratif du Paléolithique cantabrique. Bull. de la Societé Préhistorique de L'Ariege, 40: 99-129.

Moure, A., 1989: La caverne de Tito Bustillo (Asturies, Espagne). Le gissement paléolithique. L'Anthropologie, 93, 2: 73-86.

MouRE, A., 1990a: Relations entre l'art rupestre et l'art mobilier paléolithiques dans la region cantabrique. En L'Art des objets au Paléolithique, I: 207-216. Colloque International, Foix-le Mas d'Azil.

Moure, A., 1990b: La cueva de Tito Bustillo. Excavaciones Arqueológicas en Asturias, 19831986. Junta del Principado de Asturias, Oviedo.

MOURE, A., 1992: La cueva de Tito Bustillo. El arte y los cazadores del Paleolítico. Trea, Avilés.

MOURE, A. (ed.), 1992: Elefantes, ciervos y ovicápridos. Economía y aprovechamiento del medio en la Prehistoria de España y Portugal. Universidad de Cantabria, Santander. 
MOURE, A., 1994: Arte paleolítico y geografias sociales. Asentamiento, moviliad y agragación en el final del Paleolítico cantábrico. En Chapa y Menéndez (edit.), 1994: 313-330.

Moure, A., 1995: Después de Altamira: transformaciones en el hecho artístico al final del Pleistoceno. En Moure y González Sáinz, 1995: 225-258. Santander.

Moure, A. (edit.) 1996a: «El hombre fósil» 80 años después. Homenaje a Hugo Obermaier. Univ. de Cantabria. Santander.

Moure, A., 1996b: Art pariétal, art mobilier et habitat: état de la recherche. En L'art préhistorique des Pyrénées, Catálogo de la exposición del Musée des Antiquités nationales (SaintGermain-en-Laye), pp.72- 79.

Moure, A., 1997: Dataciones AMS de la Gueva de Tito Bustillo (Asturias). Trabajos de Prehistoria, 54, 2: 135-142.

Moure, A., y Gonż́lez, C. (edits.) 1995: El final del Paleolítico cantábrico. Univ. de Cantabria. Santander

Obermaier, H, Vega del Sella, 1918: La Cueva del Buxu. C.I.P.P., 20. Madrid.

Olaria, C.; Gusi, F.; Estévez, J.; CASABO, J., y RoviRA, M.L., 1981: El yacimiento magdaleniense superior de Cova Matutano (Villafamés,Castellón): Estudio del sondeo estratigráfico 1979. Cuadernos de Prehistoria y Arqueología Castellonenses, 8, 21-100.

PAPi RodÉs, C., 1989: Los elementos de adorno colgantes en el Paleolítico Superior y Epipaleolítico: pautas para su estudio tecnológico. Trabajos de Prehistoria, 46: 47-63.

PÉREZ, M., 1977: Presentación de algunos materiales procedentes de Cueva Ocura de Ania, Las Regueras (Asturias). XIV Congreso Nacional de Arqueología, 179-196.

Pérez, M., 1982: Las varillas semicilíndricas decoradas de Cueva Oscura de Ania-Las Regueras-Oviedo. Sautuola, II!: 79-84

Pérez, M., 1992: Un hueso grabado de "Cueva Oscura de Ania" (Las Regueras,Asturias). BIDEA, 140: 625-650. Oviedo.

RAMIL SONEIRA, J., y VÁzQUEZ VARELA, J.M., 1983: Primer hallazgo de arte mueble paleolítico en Galicia. Ars Praehistorica, II: 191-193.

Ripoll López, S., y CACHO QUeSADA, C., 1987: Arte mobilier paléolithique meditérranéen espagnol: quelques nouvelles découvertes. En L'Art des objets au Paléolithique, t. I: 287293. Foix-le Mas d'Azil.

Rodriguez, J.M., 1916: Algo más de Prehistoria-Oña (Burgos). Rev. Ibérica, 142: 189-190.

RodRiguez Asensio, A., 1990: Excavaciones arqueológicas realizadas en la Cueva de «La Lluera». (San Juan de Priorio-Oviedo). Excavaciones Arqueológicas en Asturias, 1983-1986.: 15-17. Junta del Principado de Asturias, Oviedo.

SANCHIDRIÁN, J.L., 1986: El arte prehistórico de la Cueva de Nerja. En La Prehistoria de la Cueva de Nerja (Málaga). Trabajos de la Cueva de Nerja, no 1. Paleolítico y Epípaleolítico, 283-330.

SANCHIDRIÁN, J.L., 1994: Arte ruepstre de la cueva de Nerja. Trabajos sobre la cueva de Nerja, $n^{2} 4$.

SAN JUAN, C., 1983: Un grabado inédito sobre un disco de ocre de la Cueva de La Chora (Cantabria). Ars Praehistorica, II: 177-180.

SIEVEKING, A.G., 1987: Engraved Magdalenian Plaquettes. A regional and stylistic analysis of stone, bone and antler plaquettes from Upper Palaeolithic sites in France and Cantabrian Spain. BAR Int. Series 369, Oxford.

StraUS, L.G., 1982: Observations on Upper Palaeolithic art: old and new directions. Zephyrus XXXIV-XXXV. Salamanca.

Straus, L.G., 1996: Paléoécologie d'un territoire: Pyrénées et Cantabres. En L'art préhistorique des Pyrénées, Catálogo de la exposición del Musée des Antiquités nationales (Saint-Germain-en-Laye), pp. 142-155.

Straus, L., et al., 1986: La Riera Cave. Stone Age Hunther-Gatherer Adaptations in Nothern Spain. Anthropological Research Papers, 36. Arizona State University.

UtrillA, P., 1981: El Magdaleniense Inferior y Medio en la Costa Cantábrica. Centro de Investigación y Museo de Altamira, Memoria 4.

UtRILLA, P., 1982: El yacimiento de la Cueva de Abauntz (Arraiz, Navarra). Trabajos de Arqueología Navarra, 3: 203-353.

UTRILlA, P., 1984-85: Reflexiones sobre el origen del Magdaleniense. Zephyrus, 37-38: 87-97.

UTRILLA, P., 1989: El Magdaleniense inferior en la costa cantábrica. En Le Magdalénien en Europe. La structuration du Magdalénien. ERAUL, 38: 339-415. Liège.

Utrilla, P., 1989b: Los niveles paleolíticos de la Cueva de Chaves (Bastarás, Huesca). Cien años después de Sautuola, 359-377. Santander. 
UTRiLLA, P., 1990: Bases objectives de la chronologie de l'art mobilier paléolithique sur la côte cantabrique. En L'Art des objets au Paléolithique, I: 87-99. Colloque International, Foix-le Mas d'Azil.

UtrilLLA, P., 1994: Campamentos-base, cazaderos y santuarios. Algunos ejemplos del Paleolítico peninsular. En Homenaje al Dr. J.González Echegaray. Centrode Inv. y Museo de Altamina, 17: 97-117. Madrid.

Utrilla, P., 1995: El valle del Ebro durante el Tardiglaciar y comienzos del Holoceno. Las relaciones con el Magdaleniense cantábrico. En Moure y González Sáinz (edit.) 1995: 281312. Santander.

UTRILLA, P., 1996: La sistematización del Magdaleniense cantábrico: una revisión histórica de los datos. En Moure, 1996a: 211-247.

UtRILLA, P., y MAZO, C., 1996a: Arte mueble sobre soporte lítico de la Cueva de Abauntz. Complutum Extra, $6(1): 41-62$.

UtRILLA, P., y MAZO, C., 1996b: Le versant sud des Pyrénées. En L'art préhistorique des Pyrénées, Catálogo de la exposición del Musée des Antiquités nationales (Saint-Germain-enLaye), pp. 60-69.

Valladas, H.; Cachier, H.; Malrice, P.; Bernaldo de Quirós, F.; Clottes, J.; Cabrera, V.; UzQUIANO, P., y ARNOLD, M., 1992: Direct radiocarbon dates for prehistoric paintings at the altamira, El Castillo and Niaux caves. Nature, 357/7, may 1992: 68-70.

VILLAR, R., 1994: Industria ósea paleolítica del Departamento de Prehistoria y Arqueología de la Universidad de Santiago. Zephyrus, XLVII: 313-331. Salamanca.

VILLAVERDE, V., 1987: Animation et scénes sur les plaquetes du Parpalló (Gandía, Espagne): quelques considerations sur la Pictographie dans l'Art Mobilier. L'Art des objets au Paléolithique. T. 2: 227-241. Foix-le Mas d'Azil.

ViLLAVERDE, V., 1988: Consideraciones sobre la secuencia de la Cova del Parpalló y el Arte Paleolítico del Mediterráneo Español. Archivo de Prehistoria Levantina, XVIII: 11-47. Valencia.

Villaverde, V., 1992: Principaux traits evolutifs de la collection d'art mobilier de la Grotte de Parpalió. L'Anthropologie, 96: 375-396.

VillaVerde, V., 1994a: Arte paleolítico de la Cueva del Parpalló. Estudio de la colección de plaquetas y cantos con grabados y pinturas. Valencia.

VILLAVERDE, V., 1994b: Arte mueble de la España mediterránea: Breve síntesis y algunas consideraciones teóricas. Complutum, 5: 139-162.

VILLAVERDE, V., 1994c: Arte solutrense de la España mediterránea. Férbedes, 1: 149-157. Museo de Prehistoria e Arqueoloxía de Villalba. Lugo. 